\title{
Distribution of Silver Nanoparticles to Breast Milk and Their Biological Effects on Breast-Fed Offspring Mice
}

Yuki Morishita, Yasuo Yoshioka, Yuya Takimura, Yuki Shimizu, Yuki Namba, Nao Nojiri, Takuya Ishizaka, Keizo Takao, Fumiyoshi Yamashita, Kazuhiro Takuma, Yukio Ago, Kazuya Nagano, Yohei Mukai, Haruhiko Kamada, Shin-ichi Tsunoda, Shigeru Saito, Toshio Matsuda, Mitsuru Hashida, Tsuyoshi Miyakawa, Kazuma Higashisaka, and Yasuo Tsutsumi

\section{Supporting Information}


$\mathrm{Ag}^{+}$Content in Ag Nanoparticle Suspensions. For analysis in water, $\mathrm{Ag}$ nanoparticles and $\mathrm{Ag}^{+}$ were diluted to $1 \mu \mathrm{g} / \mathrm{mL}$ with distilled water. For analysis in plasma or $\mathrm{HCl}, \mathrm{Ag}$ nanoparticles and $\mathrm{Ag}^{+}$were diluted to $1 \mu \mathrm{g} / \mathrm{mL}$ with mouse plasma or $\mathrm{HCl}(\mathrm{pH} 3.5)$ and incubated at $37^{\circ} \mathrm{C}$ for 1 or 12 $\mathrm{h}$, then a portion of the incubated solutions were centrifuged for $120 \mathrm{~min}\left(40,000 \times \mathrm{g}, 4^{\circ} \mathrm{C}\right)$ with a Himac CP70MX ultracentrifuge (Hitachi Koki, Tokyo, Japan). The Ag concentrations in the supernatant and in uncentrifuged solutions were measured by inductively coupled plasma mass spectrometry (ICP-MS). $\mathrm{Ag}^{+}$content was calculated by means of the following equation: $\mathrm{Ag}^{+}$ content $(\%)=100 \times(\mathrm{Ag}$ concentration in the supernatant after centrifugation $) /(\mathrm{Ag}$ concentration in the solution before centrifugation).

Particle Properties. For analysis in water, $\mathrm{Ag}$ and $\mathrm{Au}$ nanoparticles were diluted to $0.05 \mathrm{mg} / \mathrm{mL}$ with distilled water. For analysis in isotonic solution, Ag nanoparticles were diluted to $0.05 \mathrm{mg} / \mathrm{mL}$ with $5 \%$ glucose, and Au nanoparticles $(1 \mathrm{mg} / \mathrm{mL})$ were mixed $(8: 1, \mathrm{v} / \mathrm{v})$ with mouse serum albumin (20 mg/mL; Sigma-Aldrich, St. Louis, MO, USA); then the Au suspension was diluted to 0.05 $\mathrm{mg} / \mathrm{mL}$ with phosphate-buffered saline (PBS). Because $\mathrm{AgCl}$ formed when $\mathrm{Ag}^{+}$was solvated in PBS, $\mathrm{Ag}$ nanoparticles and $\mathrm{Ag}^{+}$were dispersed in $5 \%$ glucose for isotonization. Because $\mathrm{Au}$ nanoparticles aggregated in $5 \%$ glucose, this solution was not used to disperse Au nanoparticles. For analysis in culture medium, $\mathrm{nAg} 10$ particles $(1 \mathrm{mg} / \mathrm{mL})$ were mixed $(1: 1, \mathrm{v} / \mathrm{v})$ with bovine serum albumin (40 mg/mL, Sigma-Aldrich); then the suspension was diluted to $0.05 \mathrm{mg} / \mathrm{mL}$ with Dulbecco's modified Eagle's medium (DMEM; Wako Pure Chemical Industries, Osaka, Japan) supplemented with $10 \%$ fetal calf serum and $1 \%$ antibiotic-antimycotic mix stock solution (Gibco, Carlsbad, CA, USA). The size and shape of the nanoparticles in water were observed by means of transmission electron microscopy (TEM). Prior to TEM analysis, particles were stained with $2 \%$ uranium acetate. Then they were placed on 200-mesh carbon-coated copper TEM grids (Nissin EM, Tokyo, Japan) and observed by TEM (H-7650, Hitachi High-Technologies Corporation, Tokyo, Japan). The average particle size, size distribution spectrum, and zeta potential of each particle suspension were measured with a Zetasizer Nano-ZS (Malvern Instruments, Malvern, UK). The mean size was measured by dynamic light scattering. The zeta potential was measured by laser Doppler electrophoresis. The $\mathrm{pH}$ of each particle suspensions and $\mathrm{Ag}^{+}$solution were measured with a pH meter (Horiba, Kyoto, Japan).

Ultraviolet-Visible Spectra. For analysis in water or $5 \times$ PBS, Au nanoparticles were diluted to 0.2 $\mathrm{mg} / \mathrm{mL}$ with distilled water or $5 \times$ PBS. For analysis in PBS, Au nanoparticles $(1 \mathrm{mg} / \mathrm{mL})$ were mixed $(8: 1, \mathrm{v} / \mathrm{v})$ with mouse serum albumin $(20 \mathrm{mg} / \mathrm{mL})$, and then the suspension was diluted to $0.2 \mathrm{mg} / \mathrm{mL}$ with PBS. For analysis in $\mathrm{HCl}, \mathrm{nAg} 10$ particles were diluted to $0.1 \mathrm{mg} / \mathrm{mL}$ with $\mathrm{HCl}(\mathrm{pH}$ 1.0 or 3.5$)$ and then incubated at $37^{\circ} \mathrm{C}$ for 1,4 , or $12 \mathrm{~h}$. The absorption spectrum of each suspension was measured with a NanoDrop 1000 spectrophotometer or a NanoDrop 2000 spectrophotometer (Thermo Fisher Scientific Inc., Waltham, MA, USA).

Histological Examination. After fixation in 10\% formalin neutral buffer solution, mouse mammary glands were embedded in paraffin blocks and sectioned. The mammary gland sections were stained with hematoxylin and eosin. Histopathological examination was performed by the Applied Medical Research Laboratory (Osaka, Japan). For each sample, exfoliation of the breast duct cells and calcification in the gland lumen were scored as follows: 0 (none), 1 (very mild), 2 (mild), 3 (moderate), or 4 (severe).

\section{Supplementary Methods. Morishita et al.}


TUNEL Apoptosis Assay. Mouse mammary glands were fixed in 10\% formalin neutral buffer solution and then embedded in paraffin blocks and sectioned. DNA strand breaks, which are associated with the apoptotic response, were detected with an ApopTag Peroxidase In Situ Apoptosis Detection Kit (Merck Millipore, Billerica, MA, USA) according to the manufacturer's instructions. The tissue was counterstained with methyl green. TUNEL-positive nuclei and TUNELnegative nuclei (methyl green-stained nuclei) were counted for the mammary epithelial cells. Approximately 300 mammary epithelial cells were counted for each section. The apoptotic index in each section was calculated as the percentage of TUNEL-positive nuclei relative to the total number of nuclei. The TUNEL apoptosis assays were performed by the Applied Medical Research Laboratory.

Immunohistochemical Analysis. Mouse mammary glands were fixed in 10\% formalin neutral buffer solution and then embedded in paraffin blocks and sectioned. The sections were deparaffinized and hydrated. Antigen retrieval was performed by boiling the sections in antigen activation liquid ( $\mathrm{pH}$ 9, Nichirei Bioscience, Tokyo, Japan) for $20 \mathrm{~min}$. The sections were cooled to room temperature and immersed in 3\% hydrogen peroxide for $10 \mathrm{~min}$ to quench endogenous peroxidase activity. The sections were then incubated with blocking solution (Dako, Glostrup, Denmark) to saturate the nonspecific sites of antibody binding and were exposed to primary antibodies (anti-claudin-3, 1:500, Invitrogen, Carlsbad, CA, USA) overnight at $4^{\circ} \mathrm{C}$ in the blocking solution. After being washed, the sections were incubated with EnVision+ Single Reagents (Dako) for $30 \mathrm{~min}$ at room temperature. Peroxidase activity was detected with diaminobenzidine (Nichirei Bioscience). Sections were counterstained with hematoxylin. For each sample, the staining intensity of claudin-3 in mammary epithelial cells was scored as follows: 0 (none), 1 (low), 2 (moderate), or 3 (high). The immunohistochemical analysis was performed by the Applied Medical Research Laboratory.

Quantitation of Total Protein, Serum Albumin, $\mathrm{Cl}^{-}$, Lactose, Secretory IgA, and $\beta$-casein in Skim Milk. Total protein, serum albumin, $\mathrm{Cl}^{-}$, lactose, and secretory $\lg A$ in skim milk were measured with a Pierce BCA Protein Assay Kit (Thermo Fisher Scientific Inc.), a Mouse Albumin ELISA Kit (Shibayagi, Gunma, Japan), a QuantiChrom Chloride Assay Kit (BioAssay Systems, Hayward, CA, USA), an EnzyChrom Lactose Assay Kit (BioAssay Systems), and a Mouse Secretory Immunoglobulin A ELISA kit (Cusabio Biotech Co., Newark, DE, USA), respectively, according to the manufacturers' instructions.

Cell Culture. EpH4-Ev cells (mouse mammary epithelial cells) were purchased from the American Type Culture Collection (Manassas, VA, USA). The supplier confirmed that the lot we purchased was not contaminated by mycoplasma. The cells were maintained in DMEM supplemented with $10 \%$ fetal calf serum and $1 \%$ antibiotic-antimycotic mix stock solution at $37^{\circ} \mathrm{C}$ in $5 \% \quad \mathrm{CO}_{2}$ atmosphere. EpH4-Ev cells were seeded onto permeable polyethylene terephthalate supports (Transwell inserts, $0.4 \mu \mathrm{m}$ pore size, $0.3 \mathrm{~cm}^{2}$ cell growth area; Corning, Corning, NY, USA) in 24well plates at a density of $3.6 \times 10^{4}$ cells $/ 0.5 \mathrm{~mL}$ per insert. The medium was exchanged every day. The EpH4-Ev layers were used for experiments 6 days after seeding.

\section{Supplementary Methods. Morishita et al.}




\section{Methods}

Particle Preparation for in Vitro Experiments. $\mathrm{nAg} 10(1 \mathrm{mg} / \mathrm{mL})$ particles were mixed $(1: 1, \mathrm{v} / \mathrm{v})$ with bovine serum albumin $(40 \mathrm{mg} / \mathrm{mL})$; then the suspension was diluted to $0.05 \mathrm{mg} / \mathrm{mL}$ with DMEM supplemented with $10 \%$ fetal calf serum and $1 \%$ antibiotic-antimycotic mix stock solution. The resulting suspension was diluted to $0.2,1,5$, or $25 \mu \mathrm{g} / \mathrm{mL}$ with DMEM supplemented with $10 \%$ fetal calf serum, $1 \%$ antibiotic-antimycotic mix stock solution, and $2 \mathrm{mg} / \mathrm{mL}$ bovine serum albumin.

Assays for Epithelial Layer Integrity. EpH4-Ev cell layers were treated with $1 \mathrm{~mL}$ of $\mathrm{nAg} 10(0.2$, 1,5 , or $25 \mu \mathrm{g} / \mathrm{mL}$ ) or medium containing bovine serum albumin (control) on the basolateral side at $4^{\circ} \mathrm{C}$ or $37^{\circ} \mathrm{C}$. The transepithelial electric resistance (TEER) was measured prior to treatment and at 4 or $24 \mathrm{~h}$ after treatment with a Millicell ERS-2 meter (Merck Millipore) with a chopstick electrode according to the manufacturer's protocol. TEER was calculated as electrical resistance (ohms) multiplied by the surface area of the cell monolayer $\left(\mathrm{cm}^{2}\right)$. Relative TEER values were calculated by dividing each TEER value by the TEER value of the pretreatment well. We conducted fluorescein isothiocyanate (FITC)-labeled dextran transport assays as follows. At 4 or $24 \mathrm{~h}$ after nAg10 treatment, the medium in the apical and basolateral compartments was removed. Transport buffer (Hanks' balanced salt solution [Gibco] supplemented with $0.35 \mathrm{mg} / \mathrm{mL} \mathrm{NaHCO}{ }_{3}, 2.5 \mathrm{mg} / \mathrm{mL}$ glucose, and $2.4 \mathrm{mg} / \mathrm{mL}$ HEPES [all from Nacalai Tesque, Kyoto, Japan], $\mathrm{pH} 7.4$ ) was added to the apical side (sample volume: $0.5 \mathrm{~mL}$ ), and $0.4 \mathrm{mg} / \mathrm{mL}$ FITC-labeled dextran (average molecular weight, 3,000-5,000; Sigma-Aldrich) diluted with transport buffer was added to the basolateral side (sample volume: $1 \mathrm{~mL}$ ). At 30,60 , and $90 \mathrm{~min}$, an aliquot $(0.1 \mathrm{~mL})$ of transport buffer was collected from the apical side. For volumetric correction, $0.1 \mathrm{~mL}$ of fresh transport buffer was added to the apical side at 30 and $60 \mathrm{~min}$. The intensity of fluorescence emission was determined with a microplate reader at excitation and emission wavelengths of 490 and $525 \mathrm{~nm}$, respectively. The rate of FITC-labeled dextran transport was calculated by using a calibration curve for FITC-labeled dextran. The apparent permeability coefficient $\left(P_{\text {app }}\right)$ was determined as follows:

$P_{\text {app }}(\mathrm{cm} / \mathrm{s})=(\Delta Q / \Delta t) / A / C_{0}$

where $\Delta Q / \Delta t(\mu \mathrm{g} / \mathrm{s})$ is the rate of the appearance of the FITC-labeled dextran in the apical compartment, $A$ is the diffusion area $\left(0.3 \mathrm{~cm}^{2}\right)$, and $C_{0}$ is the initial FITC-labeled dextran concentration on the basolateral side $(400 \mu \mathrm{g} / \mathrm{mL})$.

Transfer of nAg10 Across a Mammary Epithelial Layer. EpH4-Ev cell layers grown on Transwell inserts were treated with $1 \mathrm{~mL}$ of $\mathrm{nAg} 10(1,5$, or $25 \mu \mathrm{g} / \mathrm{mL})$ or medium containing bovine serum albumin (control) on the basolateral side for 4,8 , or $24 \mathrm{~h}$. After incubation at $4^{\circ} \mathrm{C}$ or $37^{\circ} \mathrm{C}$, medium was collected from the apical side of the cell layers. The concentration of $\mathrm{Ag}$ in the collected medium was measured by ICP-MS, and the Ag content (ng) was calculated.

\section{Supplementary Methods. Morishita et al.}




\section{Methods}

Localization of Ag Nanoparticles in Breast Milk. On PND 3, lactating dams were separated from their pups and then intravenously injected with $\mathrm{Ag}$ nanoparticles $(1.5 \mathrm{mg} / \mathrm{kg})$ or $5 \%$ glucose. After administration of the test substances, the dams were kept separated from their pups for the duration of the experiment. Breast milk was collected at $12 \mathrm{~h}$ postadministration. Collected breast milk was centrifuged for 15 min $\left(2,000 \times g, 4^{\circ} \mathrm{C}\right)$. Then the top layer (milk fat globules) was removed, the remaining supernatant was filtered to obtain skim milk, and the precipitate was washed twice with PBS to obtain cells. Cells were suspended in $100 \mu \mathrm{L}$ of PBS. The Ag concentrations in the skim milk and cell suspension were measured by ICP-MS. The cells in the cell suspension were counted with a NucleoCounter (ChemoMetec, Allerod, Denmark), and the Ag content in a cell (fg/cell) was calculated. To confirm that $\mathrm{nAg} 10$ particles suspended in breast milk were not lost during separation of the skim milk from the whole milk, nAg10 particles were suspended in breast milk. The Ag concentrations in the whole milk and the skim milk prepared from the whole milk were measured, and the percentage of the Ag concentration in the skim milk relative to the $\mathrm{Ag}$ concentration in the whole milk was calculated.

TEM Analysis of nAu10P in Mammary Glands. Lactating dams were separated from their pups and then intravenously injected with nAu10P (4 mg/kg). After administration of nAu10P, the dams were kept separated from their pups for the duration of the experiment. At $12 \mathrm{~h}$ postadministration, mammary glands were fixed overnight with $2 \%$ paraformaldehyde and $2 \%$ glutaraldehyde. The fixed glands were washed with phosphate buffer, postfixed with $2 \%$ osmium tetroxide for $2 \mathrm{~h}$, dehydrated with a series of ethanol solutions of various concentrations, infiltrated with propylene oxide, and embedded in resin (Quetol-812, Nisshin EM Co., Tokyo, Japan). The polymerized resins were sliced into ultrathin sections, which were mounted on copper grids. The grids were observed by TEM (JEM-1400Plus; JEOL, Tokyo, Japan). The presence of Au was confirmed by energy dispersive X-ray spectroscopy (JED-2300T, JEOL).

Distribution of $\mathrm{Ag}$ Nanoparticles and $\mathrm{AgNO}_{3}$ Administered to Pups and Adult Mice via a Single Oral Dose. Either $\mathrm{nAg} 10(2.5 \mathrm{mg} / \mathrm{kg})$ or $\mathrm{AgNO}_{3}(2.5 \mathrm{mg} / \mathrm{kg} \mathrm{Ag})$ was orally administered to pups (PND 3) and adult mice (6 weeks old). At $0.25,0.5,1,2,4$, and $8 \mathrm{~h}$ postadministration, blood was collected, and the concentration of Ag in blood was measured by ICP-MS.

Distribution of $\mathbf{n A g} 10$ to Pups via Breast Milk after Administration of a Single Dose to Dams Using a Metabolic Cage. On PND 3, nAg10 (10 mg/kg) was orally administered to lactating $\mathrm{BALB} / \mathrm{c}$ mice, and the lactating mice and their pups were placed in either a metabolic cage or a conventional cage. The maternal body weights, numbers of pups per litter, and body weights of pups were adjusted to be nearly identical in the two groups before administration. Pups were breast-fed by dams in both types of cages. At $24 \mathrm{~h}$ postadministration, blood was collected from the pups, and the concentration of Ag in blood was measured by ICP-MS.

\section{Supplementary Methods. Morishita et al.}




\section{Methods}

\section{Behavioral Analysis}

Experimental Design

The following behavioral tests were conducted in the order listed: the grip strength test (a test for neuromuscular strength), the wire hang test (a test for neuromuscular strength and depressionrelated behavior), the open field test (a test for locomotor activity and anxiety-like behavior), the elevated plus maze test (a test for anxiety-like behavior), the hot plate test (a test for pain sensitivity), the social interaction test (a test for anxiety-like behavior and social interaction), the rotarod test (a test for motor ability and motor learning), the prepulse inhibition test (a test for acoustic startle response and prepulse inhibition), the Porsolt forced swim test (a test for depression-related behavior), gait analysis (a test for gait function), the tail suspension test (a test for depression-related behavior), home cage monitoring (a test for locomotor activity and social interaction), and the fear conditioning test (a test for context memory). The raw data from the behavioral tests, which are not described in this paper, have been deposited in the Mouse Phenotype Database (http://www.mouse-phenotype.org/). Behavioral testing (with the exception of home cage monitoring) was performed between 8:00 a.m. and 7:00 p.m. local time. After the tests, the apparatus was cleaned with water containing hypochlorous acid to prevent bias due to olfactory cues. All behavioral testing procedures involving the care and use of animals were carried out in accordance with institutional guidelines (National Institute for Physiological Sciences and the National Institute of Health Sciences guide for the care and use of laboratory animals).

\section{Neuromuscular Strength}

The neuromuscular strength of 11-week-old male mice was assessed by means of the grip strength test and the wire hang test. The grip strength test was performed using a grip strength meter (O'Hara \& Co., Tokyo, Japan). Mice were lifted and held by their tail so that their forepaws could grasp a wire grid. Then, the mice were gently pulled backward in a horizontal plane until they released the grid. The peak force (in Newtons) was recorded. Each mouse was tested three times, and the greatest value measured was used for statistical analysis. In the wire hang test, mice were placed on a wire mesh. Then, the wire mesh was inverted gently, and the mice were suspended from the wire mesh. Latency to fall was recorded, with a 60-s cut-off time.

\section{Open Field Test}

The open field test was performed with 11-to-12-week-old male mice. Each mouse was placed in the corner of the open field apparatus $(40 \mathrm{~cm} \times 40 \mathrm{~cm} \times 30 \mathrm{~cm}$; Accuscan Instruments, Columbus, $\mathrm{OH}$, USA). Total distance traveled (cm), vertical activity (i.e., rearing, measured by counting the number of photobeam interruptions), time spent in the center area, and beam-break counts for stereotyped behaviors were recorded. Recorded values were averaged at 5-min intervals. Data were collected for $120 \mathrm{~min}$.

\section{Supplementary Methods. Morishita et al.}




\section{Methods}

\section{Elevated Plus Maze Test}

The elevated plus maze test was performed with 12-week-old male mice. The elevated plus maze (O'Hara \& Co.) consisted of two open arms $(25 \mathrm{~cm} \times 5 \mathrm{~cm})$ and two enclosed arms of the same size, with 15-cm-high transparent walls. The arms and central square were made of plastic plates and were elevated to a height of $55 \mathrm{~cm}$ above the floor. To minimize the likelihood of animals falling from the apparatus, 3-mm-high plastic ledges were provided for the open arms. Arms of the same type were arranged opposite each other. Each mouse was placed in the central square of the maze $(5 \mathrm{~cm} \times 5 \mathrm{~cm}$ ), facing one of the closed arms. Mouse behavior was recorded during a 10-min test period. The number of entries into and the time spent in open and enclosed arms were recorded. For data analysis, we used the following four measures: the number of total entries, the percentage of entries into the open arms, total distance traveled $(\mathrm{cm})$, and the percentage of time spent in the open arms. Data acquisition and analysis were performed automatically using ImageEP software (see the Image analysis section).

\section{Hot Plate Test}

The hot plate test was performed with 12-week-old male mice. Each mouse was placed on a hot plate $\left(55.0^{\circ} \mathrm{C} \pm 0.3^{\circ} \mathrm{C}\right.$; Columbus Instruments, Columbus, $\left.\mathrm{OH}, \mathrm{USA}\right)$, and latency to the first paw response was recorded. The paw response was defined as either a foot shake or a paw lick.

\section{Social Interaction Test}

The social interaction test was performed with 12-to-13-week-old male mice. Two mice of the same group (e.g., two male offspring of dams that had received $\mathrm{nAg} 10$ at $0.5 \mathrm{mg} / \mathrm{kg}$ ) that had been housed separately were placed in a box together $(40 \mathrm{~cm} \times 40 \mathrm{~cm} \times 30 \mathrm{~cm})$ and allowed to explore freely for $10 \mathrm{~min}$. Social behavior was monitored with a CCD camera connected to a Windows computer. The total duration of contacts, number of contacts, number of active contacts, mean duration per contact, and total distance traveled (sum for the two mice) were measured. The active contact was defined as follows. Images were captured at 3 frames per second, and the distance traveled between two successive frames was calculated for each mouse. If the two mice contacted each other and the distance traveled per second (sum of the two mice) was longer than $10 \mathrm{~cm}$, the behavior was considered to be active contact. Data acquisition and analysis were performed automatically with ImageSI software (see the Image analysis section).

\section{Rotarod Test}

The rotarod test was performed with 13-to-14-week-old male mice using a Ugo Basile accelerating rotarod (Ugo Basile, Varese, Italy). Each mouse was placed on rotating drums (3-cm diameter), and the length of time for which each animal was able to maintain its balance on the rod was measured, with a 300-s cut-off time. The speed of the rotarod accelerated from 4 to $40 \mathrm{rpm}$ over a 5 -min period. Mice went through 3 trials per day for $3 \mathrm{~d}$, for a total of 9 trials per mouse.

\section{Supplementary Methods. Morishita et al.}




\section{Methods}

\section{Prepulse Inhibition Test}

Prepulse inhibition tests were performed with 16-week-old male mice. A startle reflex measurement system was used (O'Hara \& Co.) to measure startle response and prepulse inhibition. At the beginning of a test session, a mouse was placed in a plastic cylinder, where it was left undisturbed for $10 \mathrm{~min}$. White noise (40-ms duration) was used as the startle stimulus for all trial types. The startle response was recorded for $600 \mathrm{~ms}$, starting with the onset of the prepulse stimulus. The background noise level in each chamber was $70 \mathrm{~dB}$. The peak startle amplitude recorded during the 600-ms sampling window was used as the dependent variable. A test session consisted of six trial types (two types of startle-stimulus-only trials and four types of prepulse inhibition trials). The intensity of the startle stimulus was 110 or $120 \mathrm{~dB}$. The prepulse stimulus was presented $100 \mathrm{~ms}$ before the startle stimulus, and its intensity was 74 or $78 \mathrm{~dB}$. Four combinations of prepulse and startle stimuli were used (74/110, 78/110,74/120, and 78/120). Six blocks of the six trial types were presented in pseudorandom order such that each trial type was presented once within a block. The average intertrial interval was $15 \mathrm{~s}$ (range, 10-20 s). Prepluse inhibition was calculated by means of the following equation: prepulse inhibition $(\%)=100 \times$ [(startle amplitude without prepulse stimulus) - (startle amplitude with prepulse stimulus)]/(startle amplitude without prepulse stimulus).

\section{Porsolt Forced Swim Test}

The Porsolt forced swim test was performed with 16-week-old male mice. The swim-test apparatus consisted of four plastic cylinders $(20 \mathrm{~cm}$ height $\times 10 \mathrm{~cm}$ diameter). The cylinders were filled with water containing hypochlorous acid (room temperature) up to a height of $8 \mathrm{~cm}$. Mice were placed in the cylinders, and their behavior was recorded over a 10-min test period. Immobility time and distance traveled were recorded automatically, and a per-minute average was calculated. Mice went through one trial per day for two successive days (day 1 and day 2). Data acquisition and analysis were performed automatically with ImagePS software (see the Image analysis section).

\section{Gait Analysis}

Gait analysis was performed with 16-week-old male mice by means of ventral plane videography (DigiGait, Mouse Specifics, Quincy, MA, USA). Briefly, each mouse was placed on a transparent treadmill belt that moved at a speed of $24 \mathrm{~cm} / \mathrm{s}$. Digital video images of the paw placement of each mouse were collected at 150 frames per second by a video camera located beneath the treadmill belt. From the paw placement data, stance width, stride length, step angle, paw angle, and the duration of swing, braking, and propulsion were calculated by the software.

\section{Tail Suspension Test}

The tail suspension test was performed with 17-to-18-week-old male mice. Each mouse was suspended $30 \mathrm{~cm}$ above the floor in a visually isolated area by adhesive tape placed $1 \mathrm{~cm}$ from the tip of the tail. Immobility time was recorded automatically over a 10-min test period, and a perminute average was calculated. Data acquisition and analysis were performed automatically, with ImageTS software (see the Image analysis section).

\section{Supplementary Methods. Morishita et al.}




\section{Methods}

\section{Home Cage Monitoring}

Social interaction monitoring in a home cage was performed with 25-to-29-week-old male mice. The system comprised the home cage $(29 \mathrm{~cm} \times 18 \mathrm{~cm} \times 12 \mathrm{~cm})$ and a filtered cage top, separated by a 13-cm-high metal stand containing an infrared video camera attached at the top of the stand. Two mice of the same group (e.g., two male offspring of dams that had received nAg10 at 0.5 $\mathrm{mg} / \mathrm{kg}$ ) that had been housed separately were placed together in the home cage. Their social behavior was then monitored for 1 week (day 1 to day 7). Output from the video camera was fed into a Windows computer. Images from each cage were captured at a rate of one frame per second. Social interaction was measured by counting the number of particles detected in each frame: two particles indicated that the mice were not in contact with each other; and one particle (i.e., the tracking software could not distinguish the two separate bodies) indicated contact between the two mice. We also measured locomotor activity (activity level, sum of the two mice) during these experiments by quantifying the number of pixels that changed between each pair of successive frames. The number of particles and the activity level of each pair from 1:00 p.m. of day 3 to 12:00 p.m. of day 6 were averaged for each time of day. Analysis was performed automatically with ImageHA software (see the Image analysis section).

\section{Fear Conditioning Test}

The fear conditioning test was performed with 38-to-42-week-old male mice. Each mouse was placed in a test chamber $(26 \mathrm{~cm} \times 34 \mathrm{~cm} \times 29 \mathrm{~cm})$ inside a sound-attenuated chamber (O'Hara \& Co.) and allowed to explore freely for $2 \mathrm{~min}$. White noise ( $55 \mathrm{~dB})$, which served as the conditioned stimulus (CS), was presented for $30 \mathrm{~s}$, followed by a mild foot shock ( $2 \mathrm{~s}, 0.3 \mathrm{~mA})$, which served as the unconditioned stimulus (US). Two more CS-US pairings were presented, each with a 2-min interstimulus interval, over the 8-min session. Context testing was conducted 1 and $27 \mathrm{~d}$ after conditioning by placing each mouse in the same chamber for $5 \mathrm{~min}$. Cued testing with altered context was conducted 1 and $27 \mathrm{~d}$ after conditioning using a triangular box $(35 \mathrm{~cm} \times 35 \mathrm{~cm} \times 40$ $\mathrm{cm}$ ) made of white opaque plexiglas, which was located in a different room. For cued testing with altered context, each mouse was placed in this box and allowed to explore freely for $3 \mathrm{~min}$. Then, $55-\mathrm{dB}$ white noise was presented for $180 \mathrm{~s}$. The percentage of time during which the mouse was "freezing" and the distance traveled were measured, and a per-minute average was calculated over each session. Data acquisition, control of stimuli (i.e., tones and shocks), and data analysis were performed automatically with ImageFZ software (see the Image analysis section). Images were captured at one frame per second. For each pair of successive frames, the area (in pixels) over which the mouse moved was measured. When this area was less than 20 pixels, the behavior was recorded as "freezing." When the area equaled or exceeded 20 pixels, the behavior was considered "nonfreezing." This threshold value of 20 pixels was the threshold at which freezing was readily observed by humans. Freezing that lasted for periods of time shorter than the defined time threshold of $2 \mathrm{~s}$ was not included in the analysis.

\section{Image Analysis}

The applications used for the behavioral studies (ImageEP, ImageSI, ImagePS, ImageTS, ImageHA, and ImageFZ) were based on the public domain NIH Image program (developed by the U.S. National Institutes of Health and available on the Internet at http://rsb.info.nih.gov/nih-image/) and the ImageJ program (http://rsb.info.nih.gov/ij/), which were modified for each test by Tsuyoshi Miyakawa (available through O'Hara \& Co.). ImageEP and ImageFZ are freely available at the following URL: http://www.mouse-phenotype.org/software.html.

\section{Supplementary Methods. Morishita et al.}




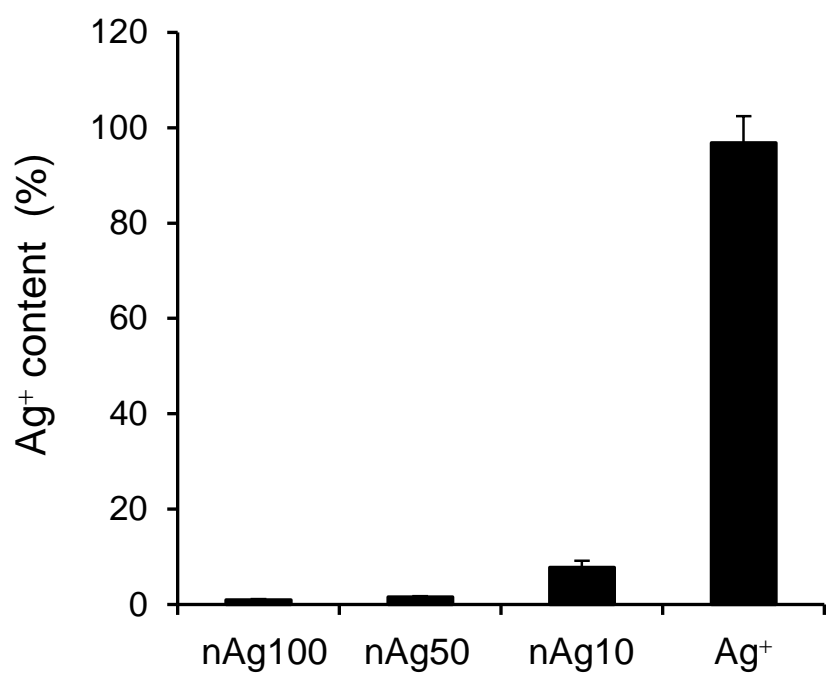

Supplementary Figure $\mathrm{S} 1 . \mathrm{Ag}^{+}$content in $\mathrm{Ag}$ nanoparticle suspensions. $\mathrm{Ag}$ nanoparticles and $\mathrm{Ag}^{+}$were diluted to $1 \mathrm{\mu g} / \mathrm{mL}$ with distilled water. After centrifugation for $120 \mathrm{~min}\left(40,000 \times \mathrm{g}, 4^{\circ} \mathrm{C}\right)$, the $\mathrm{Ag}$ concentrations in the supernatant and in uncentrifuged suspensions were measured, and $\mathrm{Ag}^{+}$content was calculated. Data were obtained from two independent experiments and are reported as means \pm $\operatorname{SDs}(n=4)$. 

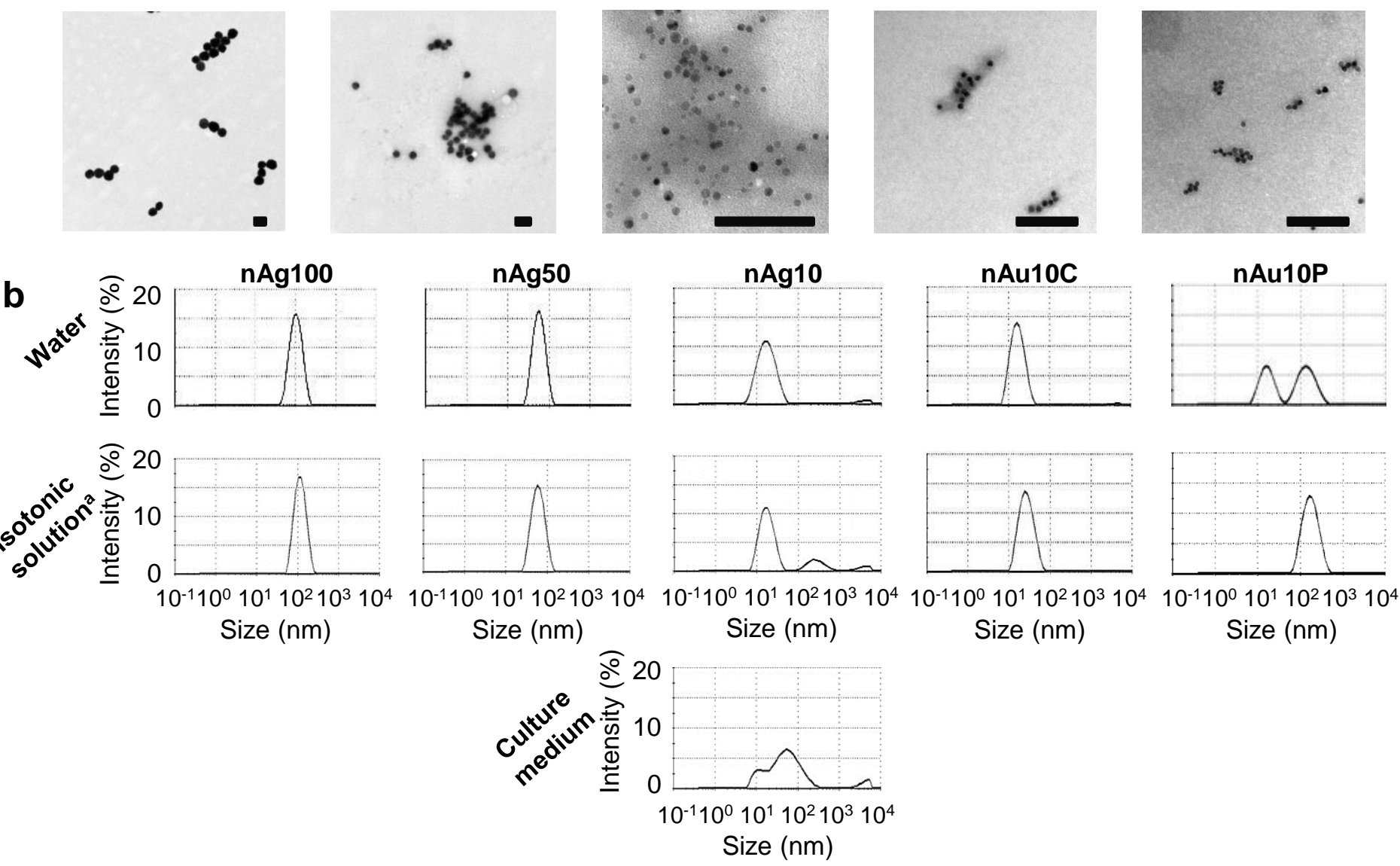

a Ag nanoparticles were dispersed in 5\% glucose, and Au nanoparticles were dispersed in PBS containing mouse serum albumin.

C

\begin{tabular}{|c|c|c|c|c|c|}
\hline & nAg100 & nAg50 & nAg10 & nAu10C & nAu10P \\
\hline Particle size in water (nm) & $96.5 \pm 0.4$ & $51.8 \pm 0.2$ & $16.1 \pm 0.3$ & $14.5 \pm 0.2$ & $33.7 \pm 1.2$ \\
\hline Particle size in isotonic solution ${ }^{a}(\mathrm{~nm})$ & $110.7 \pm 1.5$ & $54.8 \pm 0.5$ & $20.7 \pm 1.0$ & $24.1 \pm 0.2$ & $145.0 \pm 1.0$ \\
\hline Particle size in culture medium (nm) & nd & nd & $38.7 \pm 6.2$ & nd & nd \\
\hline Zeta potential in water (mV) & $-37.3 \pm 0.4$ & $-76.5 \pm 3.1$ & $-32.4 \pm 2.4$ & $-29.9 \pm 0.5$ & $-26.2 \pm 1.7$ \\
\hline Zeta potential in isotonic solution ${ }^{a}(\mathrm{mV})$ & $-24.0 \pm 0.9$ & $-40.1 \pm 1.4$ & $-25.2 \pm 1.3$ & $-14.3 \pm 0.5$ & $-15.4 \pm 8.0$ \\
\hline Zeta potential in culture medium (mV) & nd & nd & $-7.9 \pm 2.2$ & nd & nd \\
\hline $\mathrm{pH}$ in water & 6.6 & 7.5 & 7.0 & 6.4 & 4.8 \\
\hline $\mathrm{pH}$ in isotonic solution ${ }^{\mathrm{a}}$ & 4.0 & 5.5 & 4.5 & 7.5 & 7.1 \\
\hline $\mathrm{pH}$ in culture medium & nd & nd & 7.2 & nd & nd \\
\hline
\end{tabular}

a Ag nanoparticles were dispersed in $5 \%$ glucose, and Au nanoparticles were dispersed in PBS containing mouse serum albumin.

Supplementary Figure S2. Physicochemical properties of nanoparticles. a, TEM images of the particles in water. Scale bars $=100 \mathrm{~nm}$. b, Size distributions of particles obtained by dynamic light scattering. c, Particle sizes obtained by dynamic light scattering, zeta potentials, and $\mathrm{pH}$ measurements of samples. Particle sizes and zeta potentials are reported as means $\pm \operatorname{SDs}(n=3)$; nd: not determined. 


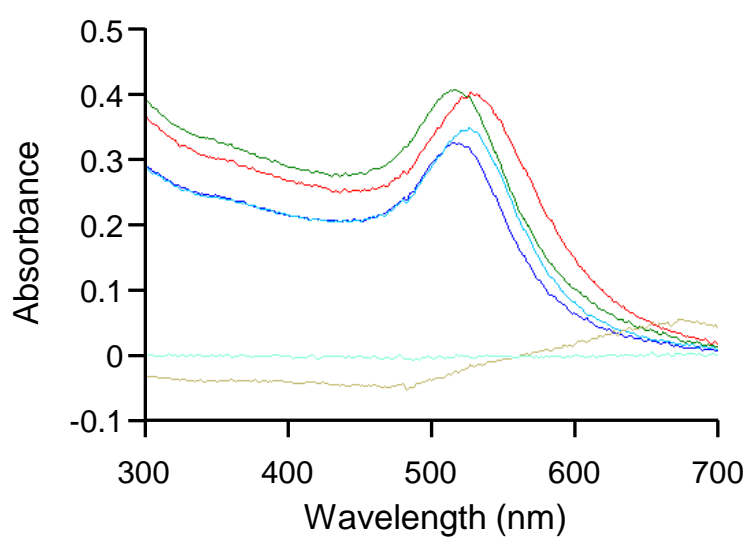

nAu10P in water

nAu10P in PBS

nAu10P in $5 \times$ PBS (aggregated nAu10P)

nAu10C in water

nAu10C in PBS

nAu10C in $5 \times$ PBS (aggregated nAu10C)

Supplementary Figure S3. Ultraviolet-visible spectra of Au nanoparticles. Au nanoparticles were diluted to 0.2 $\mathrm{mg} / \mathrm{mL}$ with distilled water, $5 \times$ phosphate-buffered saline (PBS), or PBS containing mouse serum albumin. The absorption spectrum of each suspension was analyzed. 

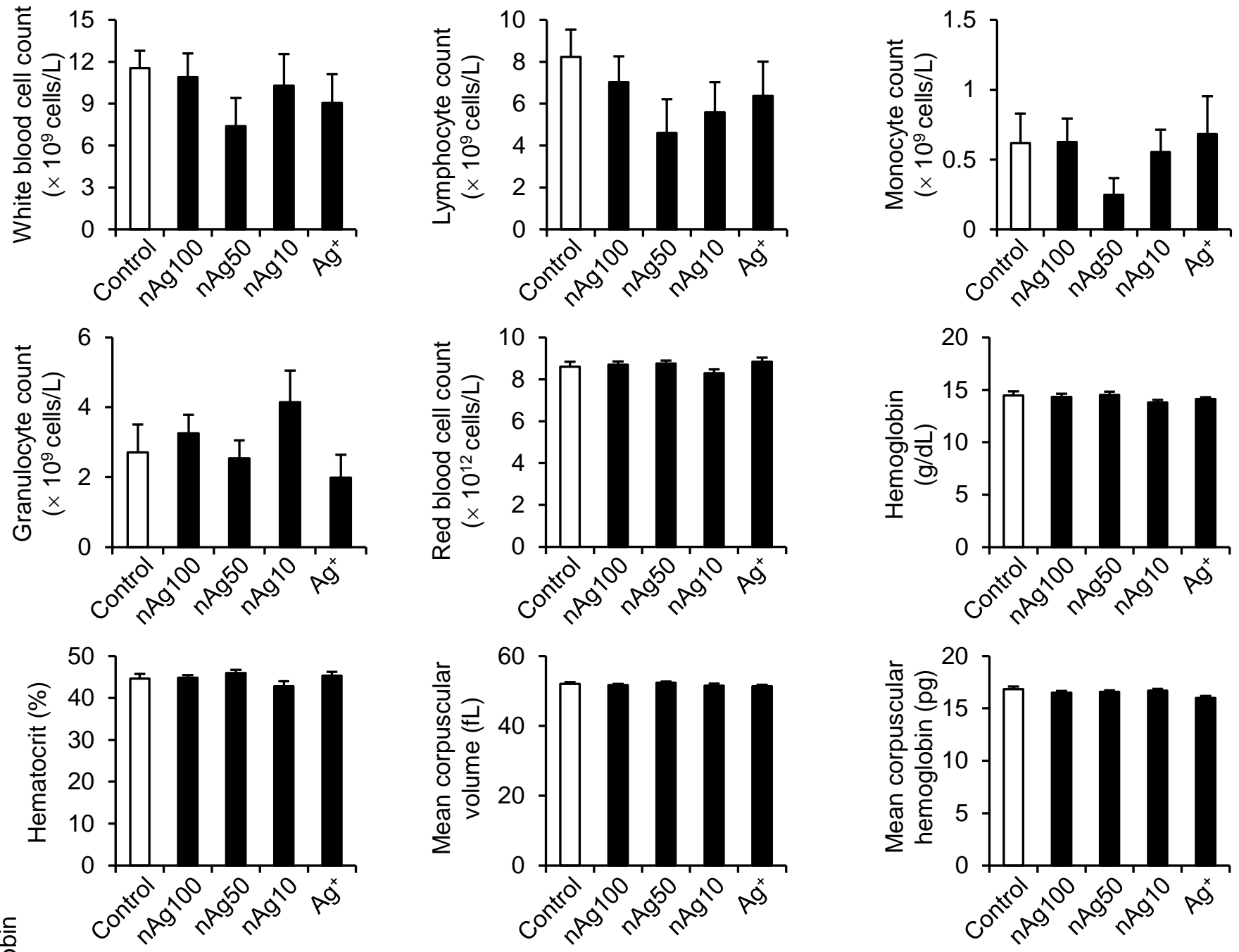

응
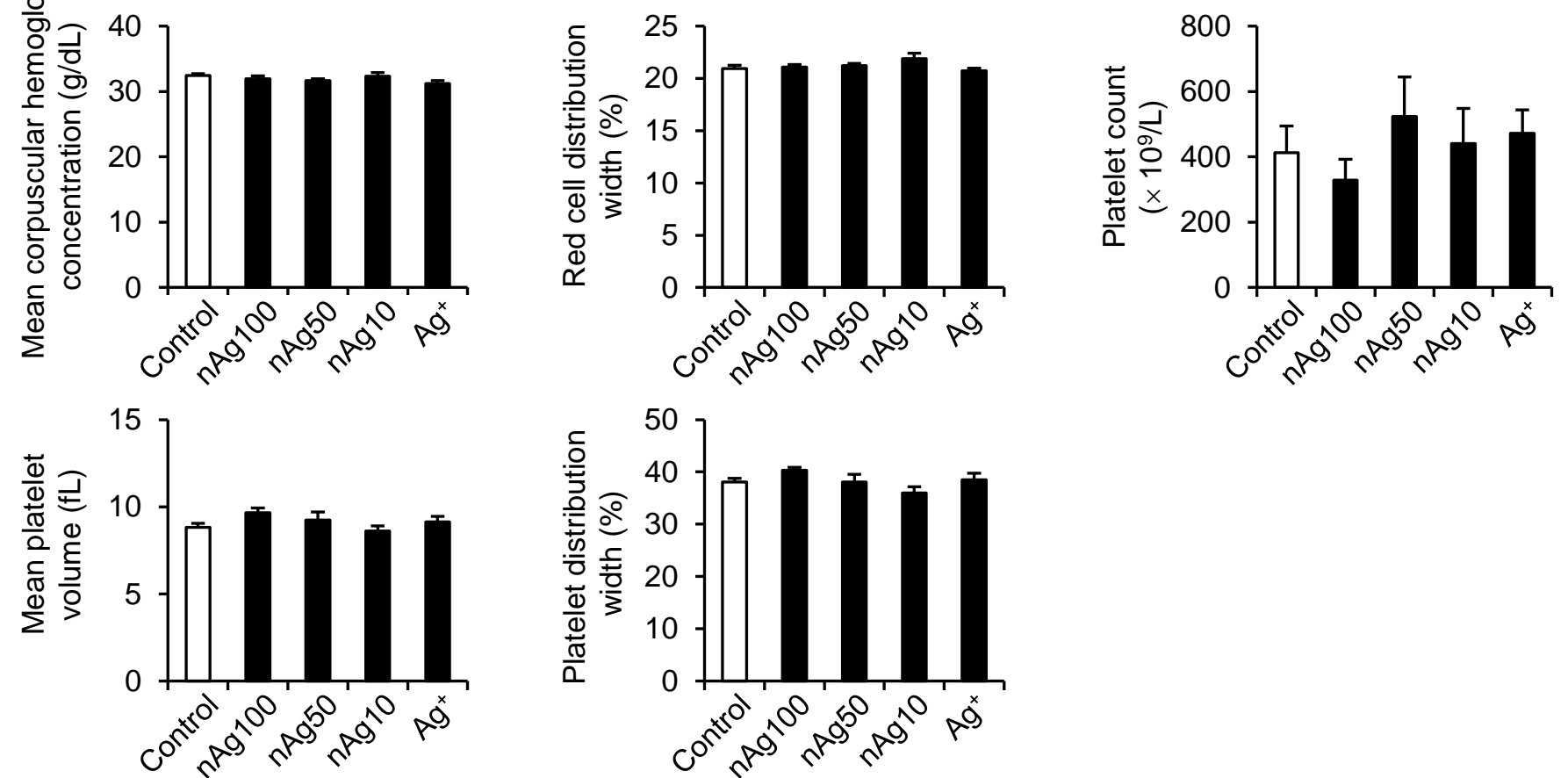

Supplementary Figure S4. Effects of a single intravenous injection of $\mathrm{Ag}$ nanoparticles or $\mathrm{Ag}^{+}$on hematology of dams. Lactating dams were intravenously injected with Ag nanoparticles (1.5 mg/kg), Ag+ (1.5 $\mathrm{mg} / \mathrm{kg}$ ), or glucose (control). Hematologic indices of dams were measured at $12 \mathrm{~h}$ postadministration. Data were obtained from two independent experiments and are reported as means \pm SEMs $(n=6-7)$.

Supplementary Figure S4. Morishita et al. 

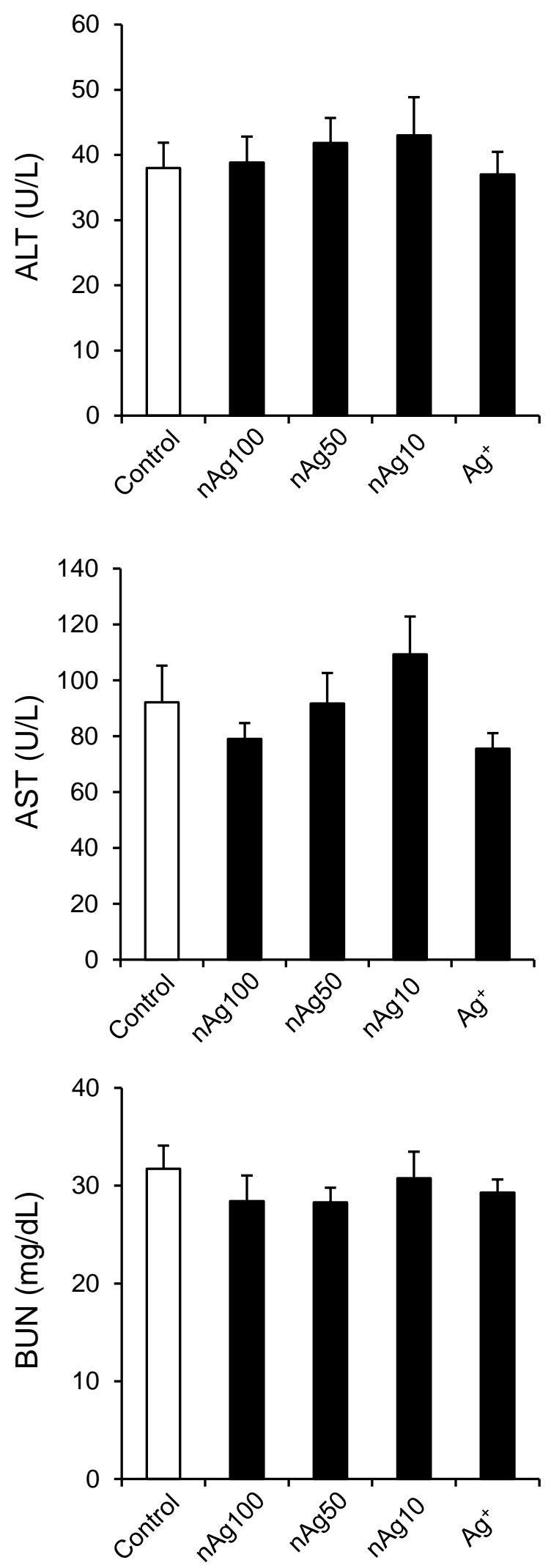

Supplementary Figure S5. Effects of a single intravenous injection of $\mathrm{Ag}$ nanoparticles or $\mathrm{Ag}^{+}$on blood chemistry of dams. Lactating dams were intravenously injected with $\mathrm{Ag}$ nanoparticles $(1.5 \mathrm{mg} / \mathrm{kg}), \mathrm{Ag}+$ (1.5 $\mathrm{mg} / \mathrm{kg}$ ), or glucose (control). Blood chemistry indices of dams were measured at $12 \mathrm{~h}$ postadministration: ALT, alanine aminotransferase; AST, aspartate aminotransferase; BUN, blood urea nitrogen. Data were obtained from two independent experiments and are reported as means \pm SEMs ( $n$ $=6-7)$. 
a Control

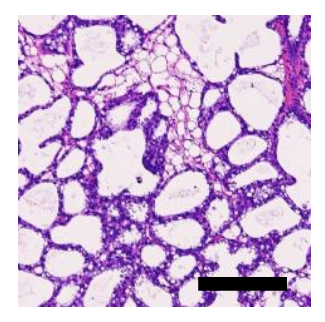

nAg100

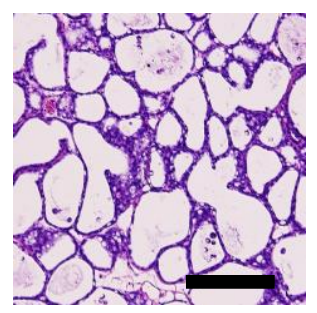

nAg50

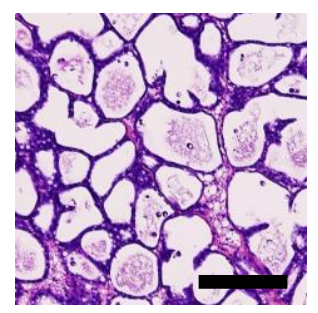

nAg10

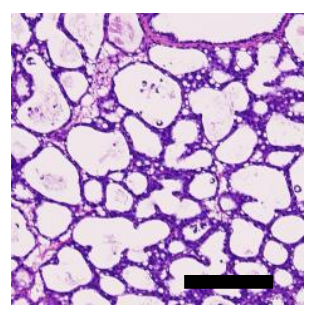

$\mathrm{Ag}^{+}$

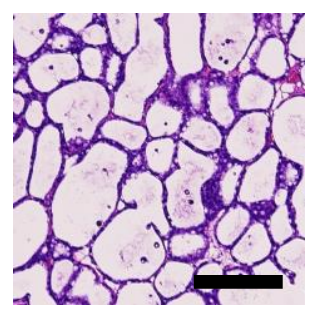

b

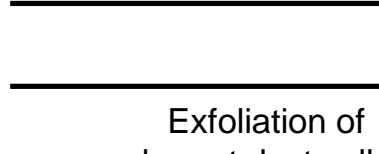

breast duct cells

Calcification in gland lumen

Control

nAg100

nAg50

nAg10

$\mathrm{Ag}^{+}$

C Control

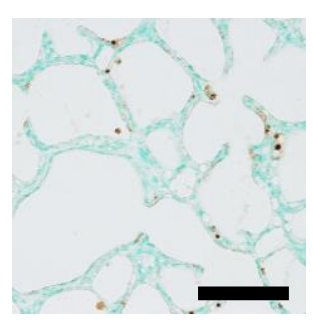

$1.4 \pm 0.3$

$1.3 \pm 0.3$

$0 \pm 0$

$0 \pm 0$

$0 \pm 0$

$1.3 \pm 0.3$

$1.2 \pm 0.2$

$0 \pm 0$

$0 \pm 0$
$1.0 \pm 0.3$

nAg10

$\mathrm{Ag}^{+}$
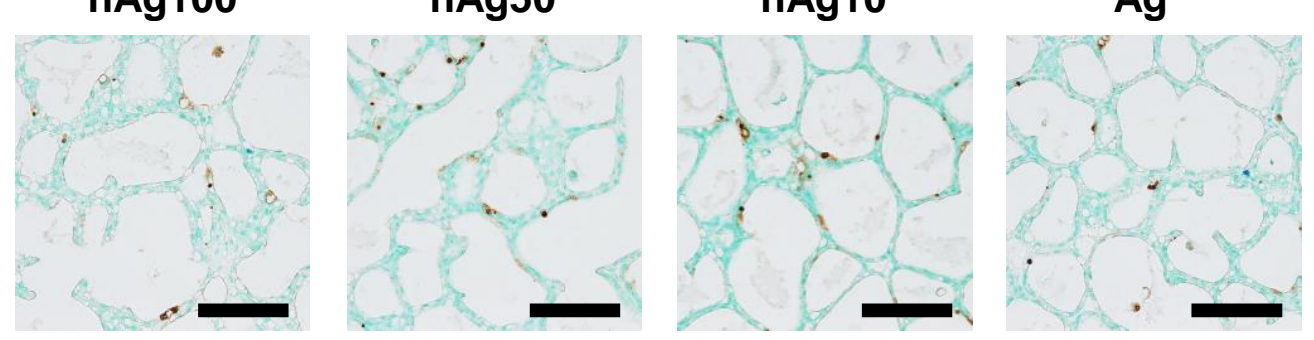

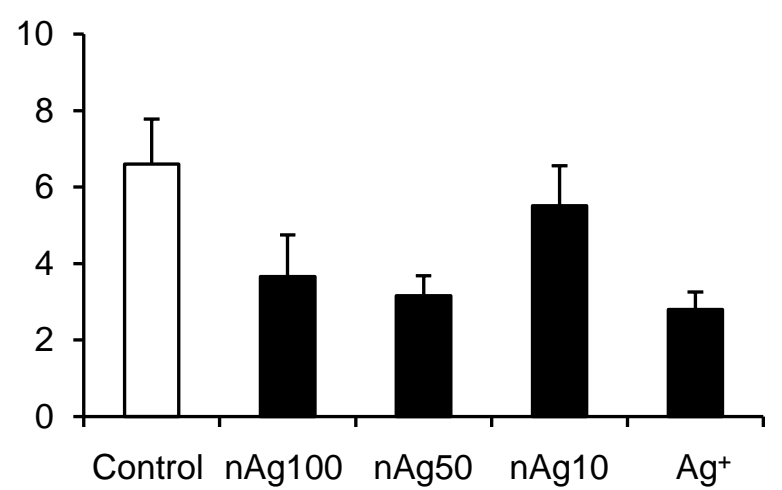

Supplementary Figure S6. Effects of a single intravenous injection of $\mathrm{Ag}$ nanoparticles or $\mathrm{Ag}^{+}$on mammary glands. Lactating dams were intravenously injected with $\mathrm{Ag}$ nanoparticles $(1.5 \mathrm{mg} / \mathrm{kg}), \mathrm{Ag}^{+}(1.5 \mathrm{mg} / \mathrm{kg})$, or glucose (control). a, At $12 \mathrm{~h}$ postadministration, sections of mammary glands were stained with hematoxylin and eosin (HE). Scale bars $=\mathbf{2 0 0} \boldsymbol{\mu m}$. b, Scores for pathological findings of mammary glands were evaluated in HE-stained sections. c, At $12 \mathrm{~h}$ postadministration, sections of mammary glands were stained with TUNEL. Scale bars $=100 \mu \mathrm{m}$. $\mathrm{d}$, The apoptotic index was assessed by examining the TUNEL-stained sections and was quantitatively analyzed. Data were obtained from two independent experiments and are reported as means \pm SEMs $(n=4-5)$. 

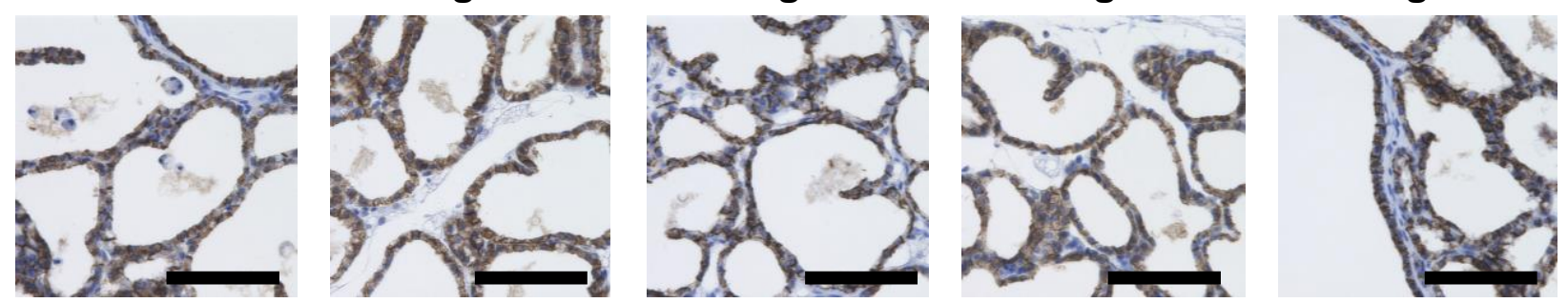

b

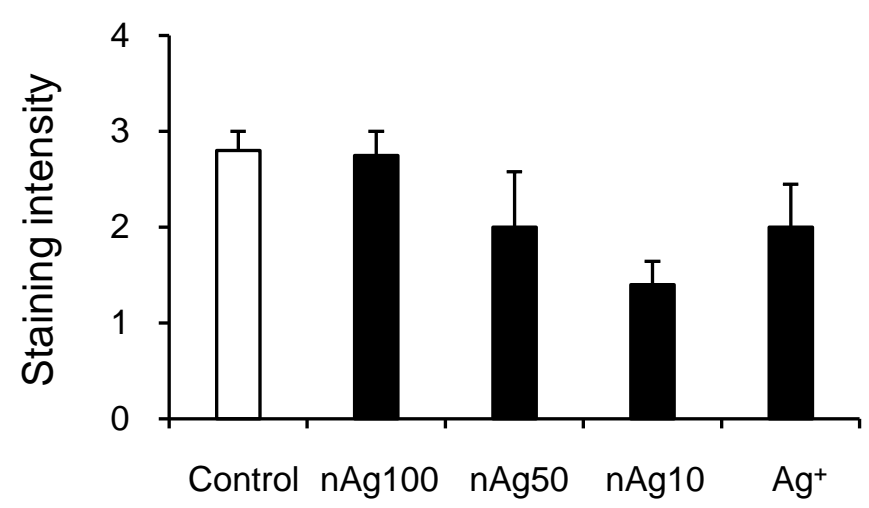

Supplementary Figure S7. Effects of a single intravenous injection of $\mathrm{Ag}$ nanoparticles or $\mathrm{Ag}^{+}$on claudin-3 in mammary glands. Lactating dams were intravenously injected with $\mathrm{Ag}$ nanoparticles $(1.5 \mathrm{mg} / \mathrm{kg}), \mathrm{Ag}^{+}(1.5$ $\mathrm{mg} / \mathrm{kg}$ ), or glucose (control). a, At $12 \mathrm{~h}$ postadministration, sections of mammary glands were immunostained with an antibody to claudin-3. Scale bars $=100 \mu \mathrm{m}$. b. The staining intensity of claudin-3 in mammary epithelial cells was evaluated in immunostained sections. Data were obtained from two independent experiments and are reported as means \pm SEMs $(n=4-5)$. 

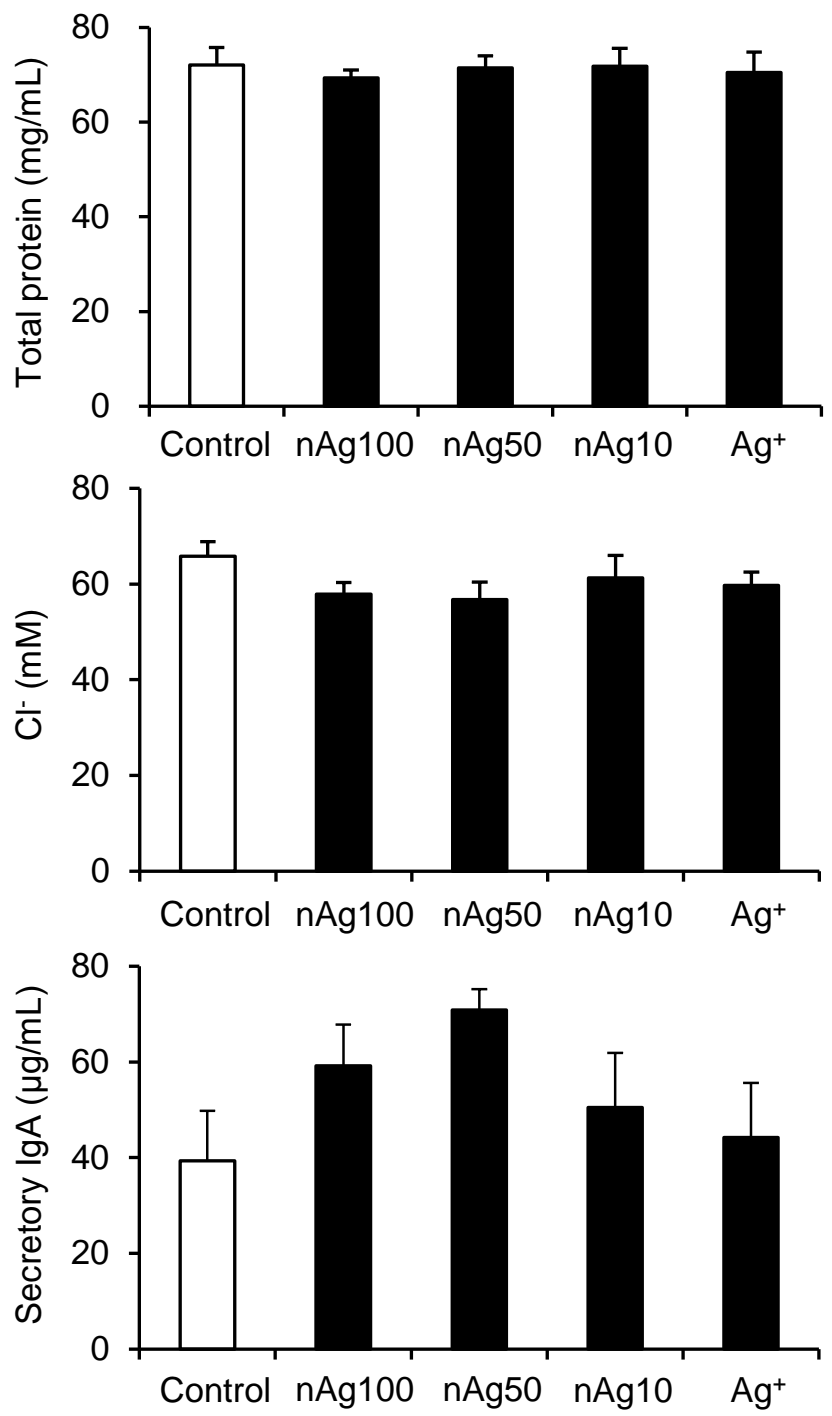
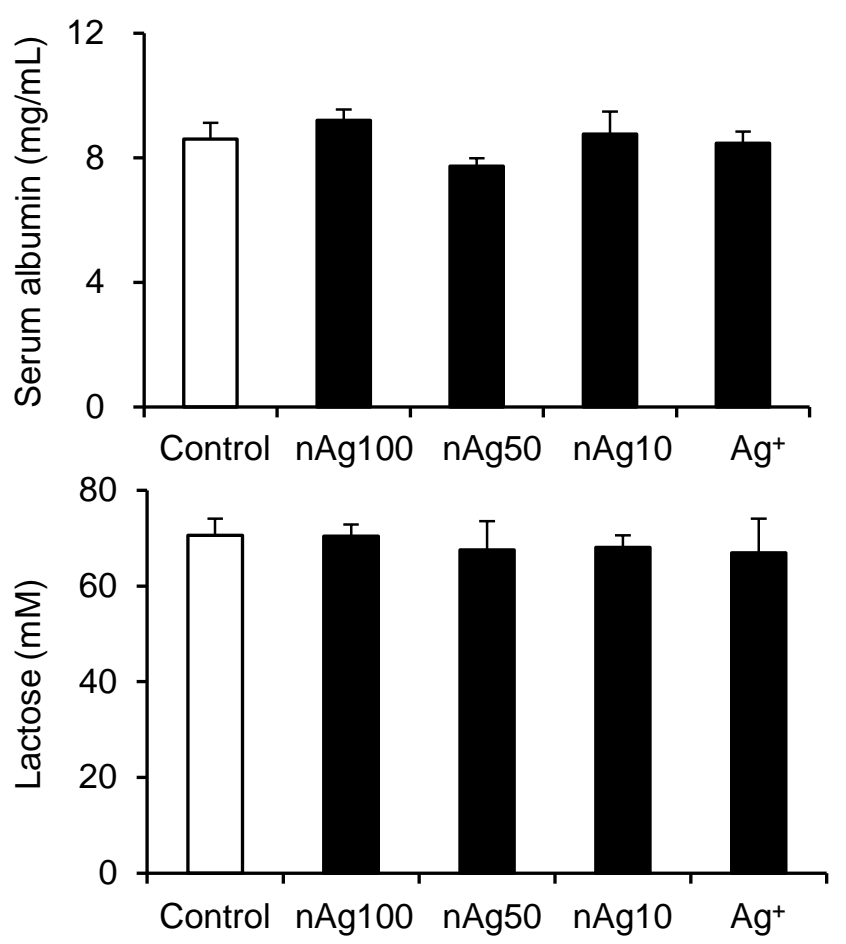

Supplementary Figure S8. Effects of a single intravenous injection of $\mathrm{Ag}$ nanoparticles or $\mathrm{Ag}^{+}$on milk composition. Lactating dams were intravenously injected with $\mathrm{Ag}$ nanoparticles $(1.5 \mathrm{mg} / \mathrm{kg}), \mathrm{Ag}^{+}(1.5 \mathrm{mg} / \mathrm{kg})$, or glucose (control). Total protein, serum albumin, $\mathrm{Cl}^{-}$, lactose, and secretory lgA concentrations in skim milk were measured at $12 \mathrm{~h}$ postadministration. Data were obtained from two independent experiments and are reported as means \pm SEMs $(n=4-6)$. 

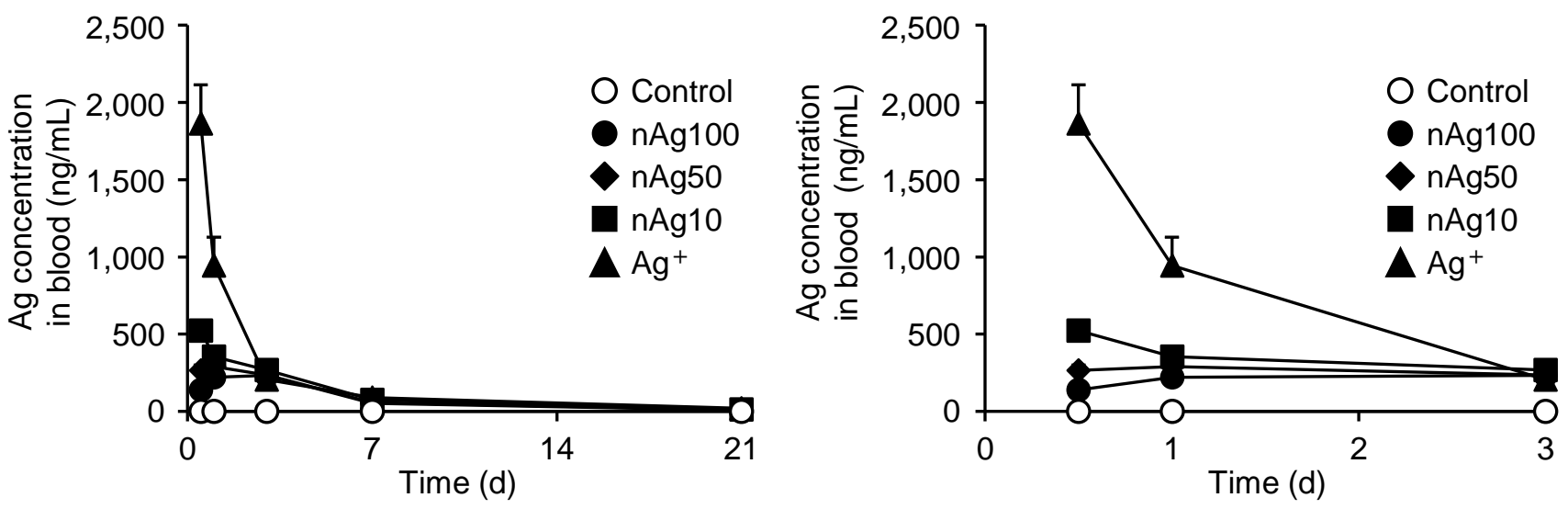

b

\begin{tabular}{ccccc}
\hline & nAg100 & nAg50 & nAg10 & Ag $^{+}$ \\
\hline Elimination rate constant & 0.176 & 0.161 & 0.154 & 0.191 \\
Half-life in blood (d) & 3.95 & 4.30 & 4.50 & 3.63 \\
\hline
\end{tabular}

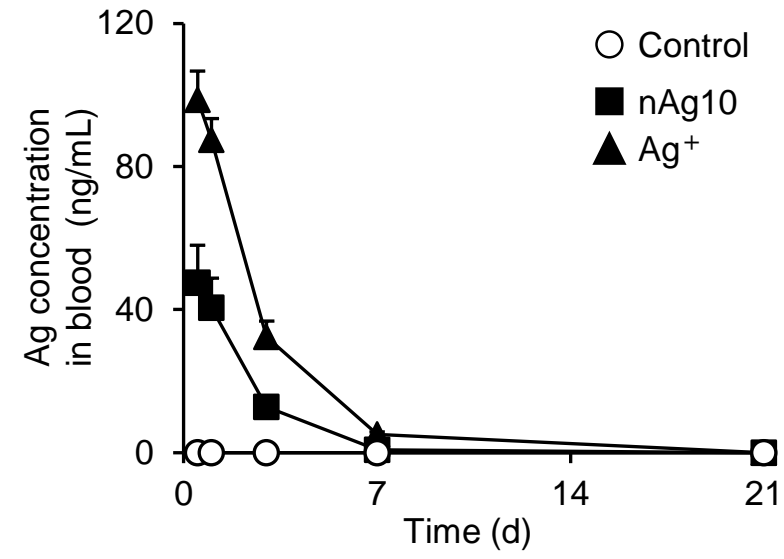

\begin{tabular}{ccc}
\hline & $\mathrm{nAg10}$ & $\mathbf{A g}^{+}$ \\
\hline Elimination rate constant & 0.654 & 0.463 \\
Half-life in blood $(\mathrm{d})$ & 1.06 & 1.50 \\
\hline
\end{tabular}

Supplementary Figure S9. Ag concentrations in blood and Ag elimination from blood of dams treated with $\mathrm{Ag}$ nanoparticles or $\mathrm{Ag}^{+}$. a,b, Lactating dams were intravenously injected with $\mathrm{Ag}$ nanoparticles (1.5 $\mathrm{mg} / \mathrm{kg}$ ), $\mathrm{Ag}^{+}(1.5 \mathrm{mg} / \mathrm{kg}$ ), or glucose (control). The Ag concentrations in the dams' blood (a, the data for 0.5-3 d postadministration are shown on the right) were measured at $0.5,1,3,7$, and $21 \mathrm{~d}$ postadministration. Elimination rate constants and half-lives in blood for Ag were calculated from the data in a (b, the following data were used for the calculations: nAg100: data from 3 to $21 \mathrm{~d}$ postadministration; nAg50: data from 1 to $21 \mathrm{~d}$ postadministration; $\mathrm{nAg} 10$ and $\mathrm{Ag}^{+}$: data from 0.5 to $21 \mathrm{~d}$ postadministration). c,d, $\mathrm{nAg} 10(10 \mathrm{mg} / \mathrm{kg}), \mathrm{Ag}^{+}(10 \mathrm{mg} / \mathrm{kg})$, or water (control) was orally administered to lactating dams. The Ag concentrations in the dams' blood (c) were measured at $0.5,1,3,7$, and $21 \mathrm{~d}$ postadministration. Elimination rate constants and half-lives in blood for Ag were calculated from the data in c (d, data from 0.5 to $7 \mathrm{~d}$ postadministration were used for the calculations). Data in $\mathrm{c}$ and $\mathrm{d}$ were obtained from two independent experiments. Data are reported as means \pm SEMs (a: $n=2-3 ; c: n=4-6)$. 

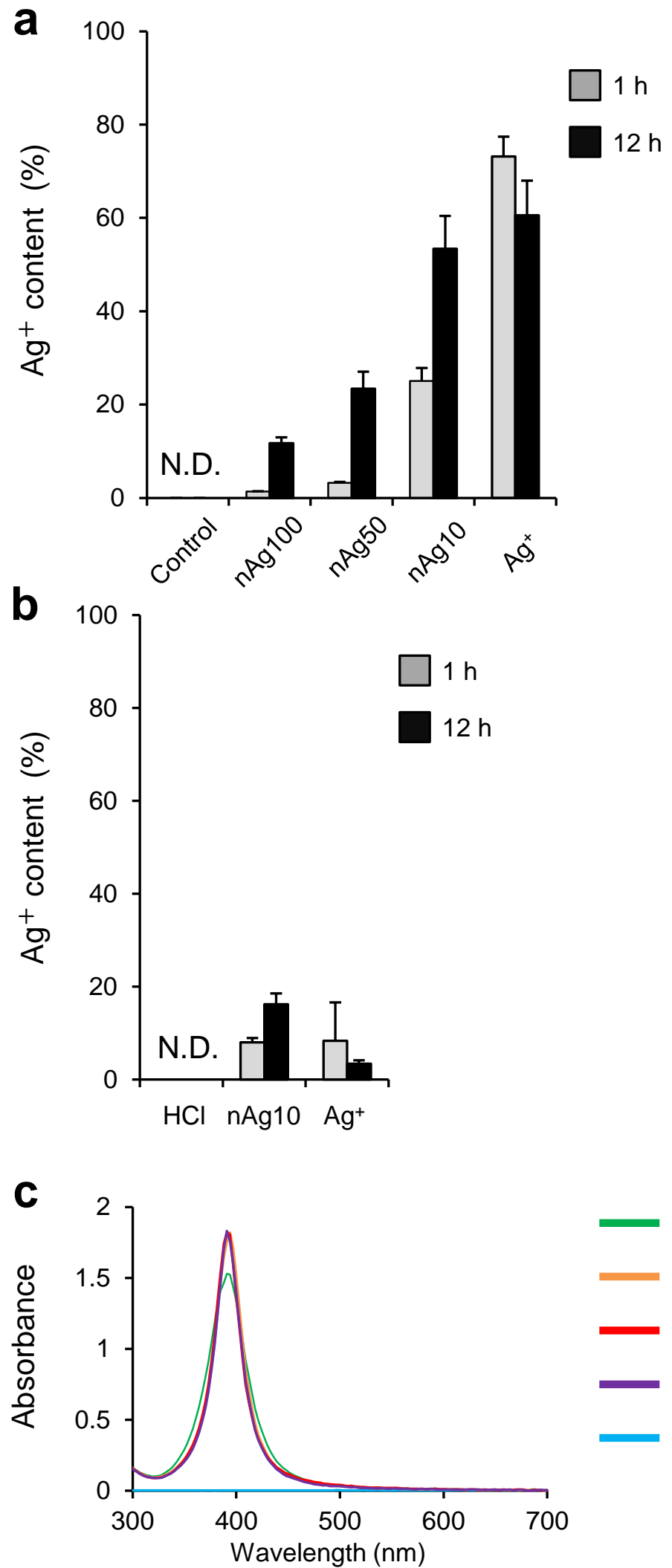

Spectrum of $\mathrm{nAg} 10$ in water

$\mathrm{HCl}(\mathrm{pH}=3.5)$ for $1 \mathrm{~h}$

$\mathrm{HCl}(\mathrm{pH}=3.5)$ for $4 \mathrm{~h}$

$\mathrm{HCl}(\mathrm{pH}=3.5)$ for $12 \mathrm{~h}$

$\mathrm{HCl}(\mathrm{pH}=1.0)$ for $1 \mathrm{~h}$

Supplementary Figure $\mathrm{S10} . \mathrm{Ag}^{+}$release from $\mathrm{Ag}$ nanoparticles incubated in plasma or $\mathrm{HCl} . \mathrm{a}, \mathrm{b}, \mathrm{Ag}$ nanoparticles and $\mathrm{Ag}^{+}$were diluted to $1 \mu \mathrm{g} / \mathrm{mL}$ with mouse plasma (a) or $\mathrm{HCl}(\mathrm{pH} 3.5)$ (b) and incubated at $37^{\circ} \mathrm{C}$ for 1 or $12 \mathrm{~h}$. After centrifugation for $120 \mathrm{~min}\left(40,000 \times \mathrm{g}, 4^{\circ} \mathrm{C}\right)$, the $\mathrm{Ag}$ concentrations in the supernatant and in uncentrifuged solutions were measured, and $\mathrm{Ag}^{+}$contents were calculated. Data are reported as means \pm SDs $(n=2-3)$. N.D.: not detected. c, nAg10 particles were diluted to $0.1 \mathrm{mg} / \mathrm{mL}$ with $\mathrm{HCl}(\mathrm{pH} 1.0$ or 3.5$)$ and then incubated at $37^{\circ} \mathrm{C}$ for 1,4 , or $12 \mathrm{~h}$. The absorption spectrum of each suspension was analyzed.

Supplementary Figure S10. Morishita et al. 
a

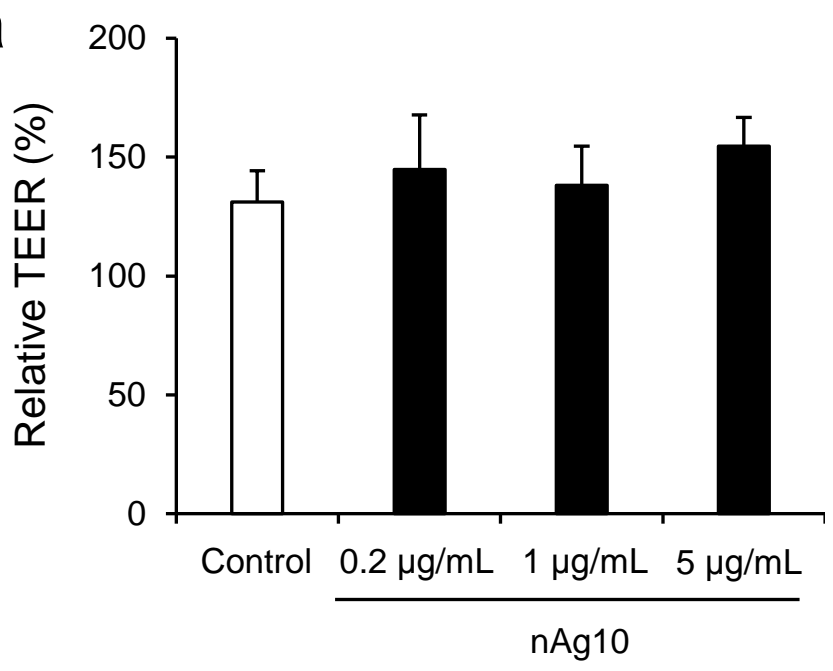

C

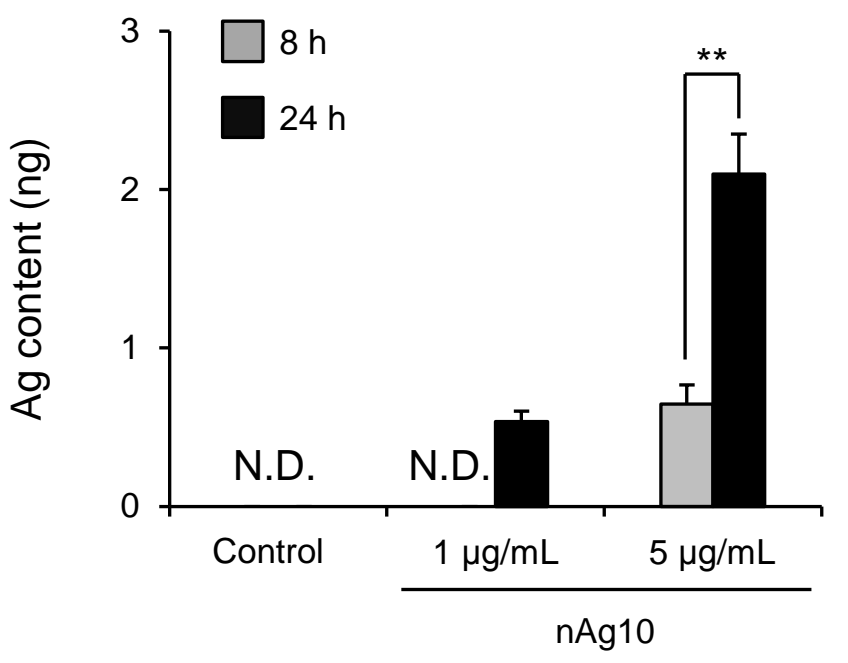

b

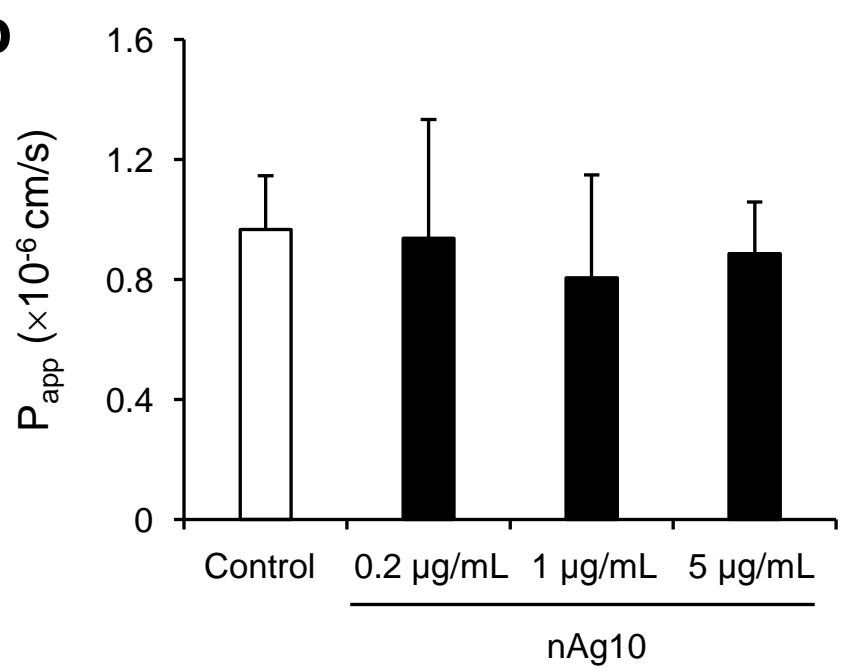

d

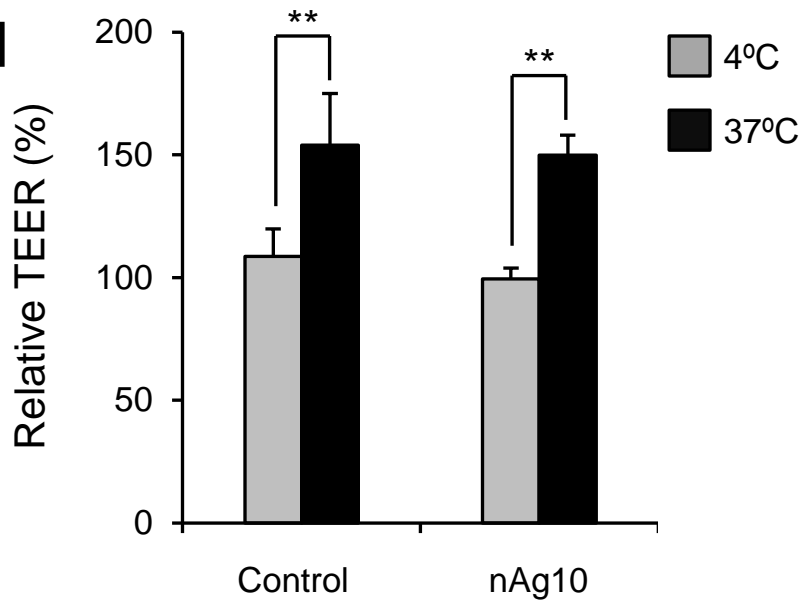

e

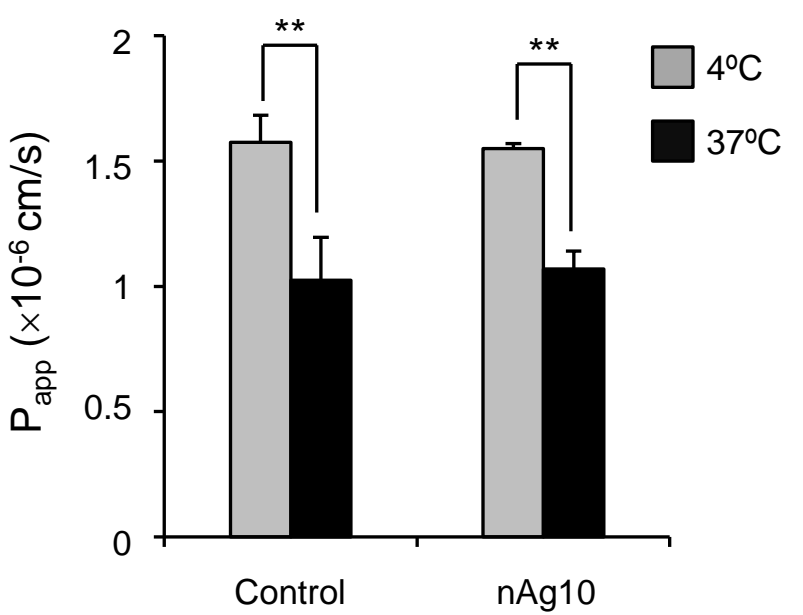

f

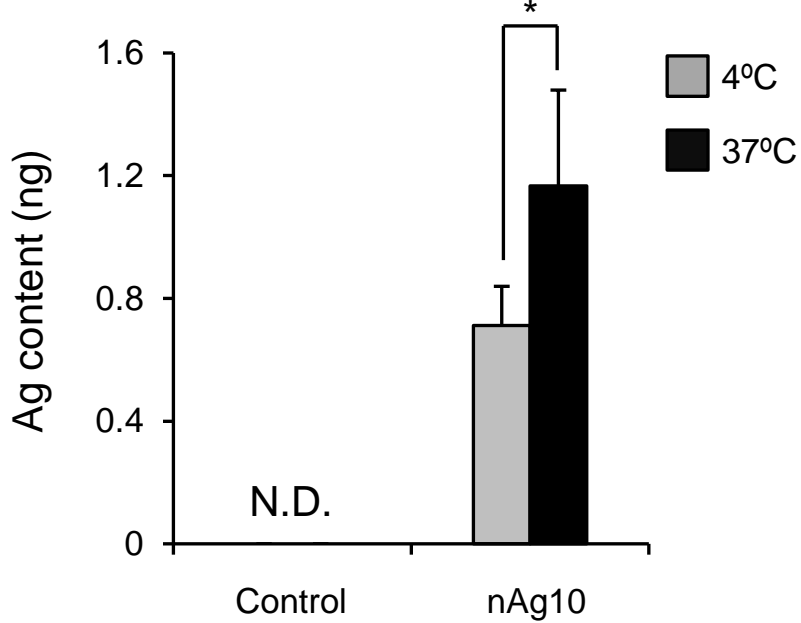

Supplementary Figure S11. Transfer of nAg10 across a mammary epithelial layer. a,b,c, A layer of EpH4Ev cells was incubated with $\mathrm{nAg} 10(0.2,1$, or $5 \mu \mathrm{g} / \mathrm{mL})$ on the basolateral side. After $24 \mathrm{~h}$, TEER values (a) and $P_{\text {app }}$ values of FITC-labeled dextran (b) were determined. After 8 and $24 \mathrm{~h}$, the Ag content in the apical medium (c) was determined by ICP-MS. d,e,f, A layer of EpH4-Ev cells was incubated with nAg10 $(25 \mu \mathrm{g} / \mathrm{mL})$ on the basolateral side for $4 \mathrm{~h}$ at $4^{\circ} \mathrm{C}$ or $37^{\circ} \mathrm{C}$. After incubation, TEER values (d), $P_{\text {app }}$ values of FITC-labeled dextran (e), and Ag content in the apical medium (f) were determined. Data in $\mathrm{c}$ and $\mathrm{f}$ were obtained from two independent experiments. Data are reported as means \pm SDs $(n=3-6)$. N.D.: not detected. ${ }^{\star} P<0.05,{ }^{\star \star} P<0.01$. 

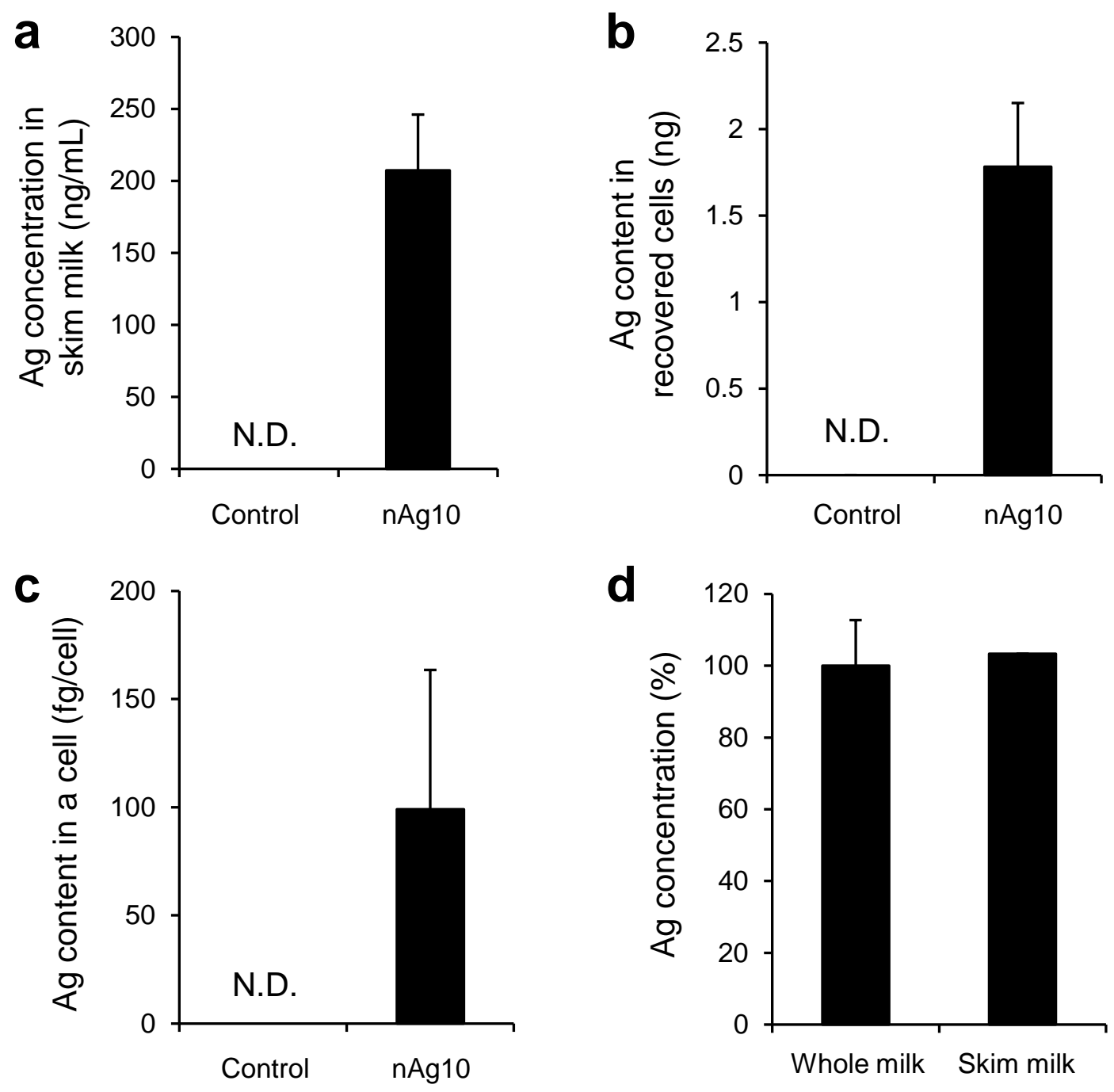

Supplementary Figure S12. Localization of $\mathrm{nAg10}$ in breast milk. a,b,c, Lactating dams were intravenously injected with $\mathrm{nAg} 10(1.5 \mathrm{mg} / \mathrm{kg})$ or glucose (control). The Ag concentrations in skim milk (a) and the Ag content in recovered cells (b) were determined at $12 \mathrm{~h}$ postadministration. The Ag content in a cell was also calculated (fg/cell) (c). Data were obtained from two independent experiments and are reported as means \pm SEMs $(n=5)$. N.D.: not detected. $d, n A g 10$ particles were suspended in breast milk, the milk was centrifuged for $15 \mathrm{~min}\left(2,000 \times \mathrm{g}, 4^{\circ} \mathrm{C}\right)$, and the supernatant was filtered to obtain skim milk. The Ag concentrations in whole milk and skim milk were measured, and the percentage of the Ag concentration in skim milk was calculated relative to the Ag concentration in whole milk. Data are reported as means $\pm \operatorname{SDs}(n=2)$. 

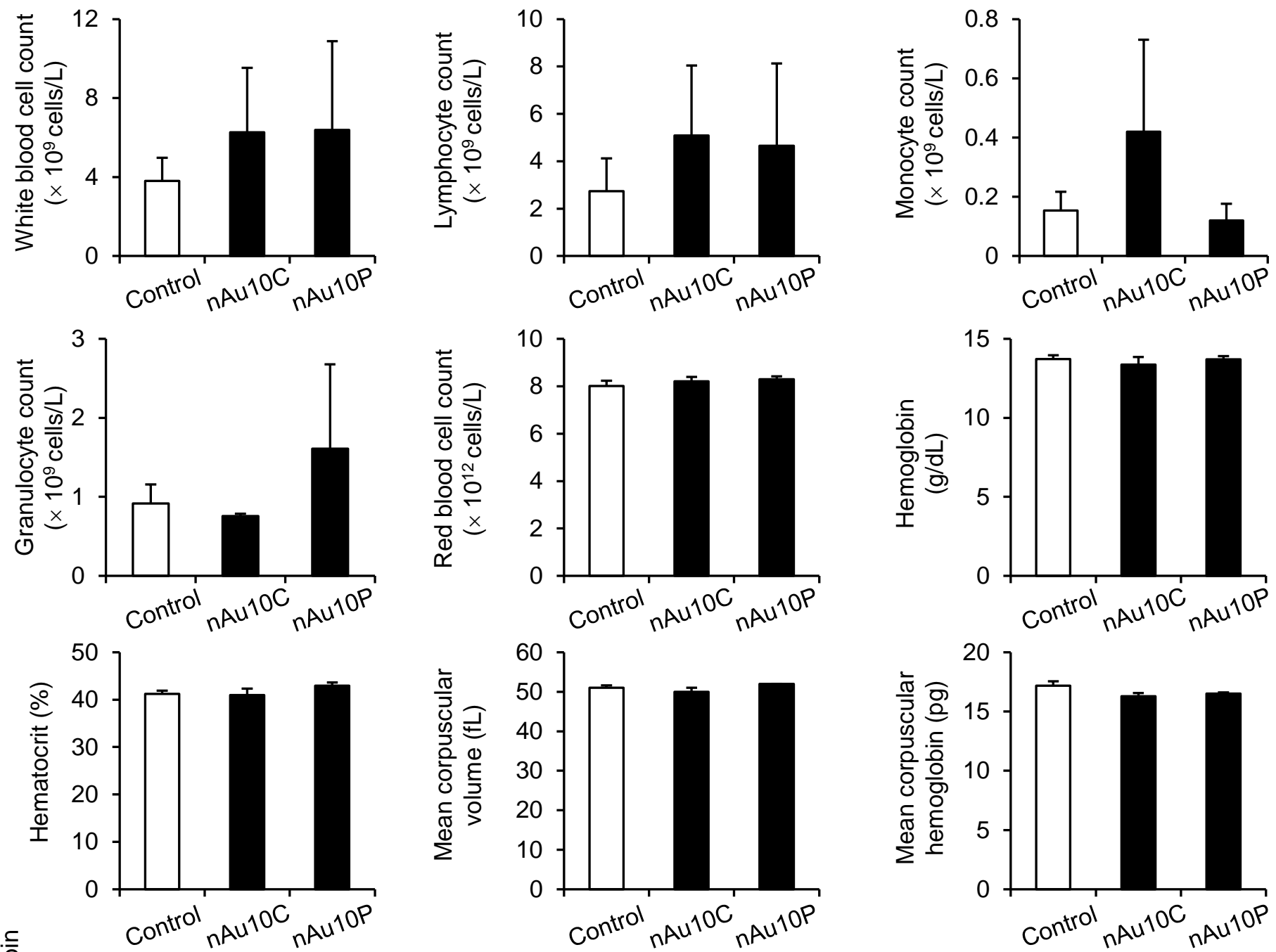

응
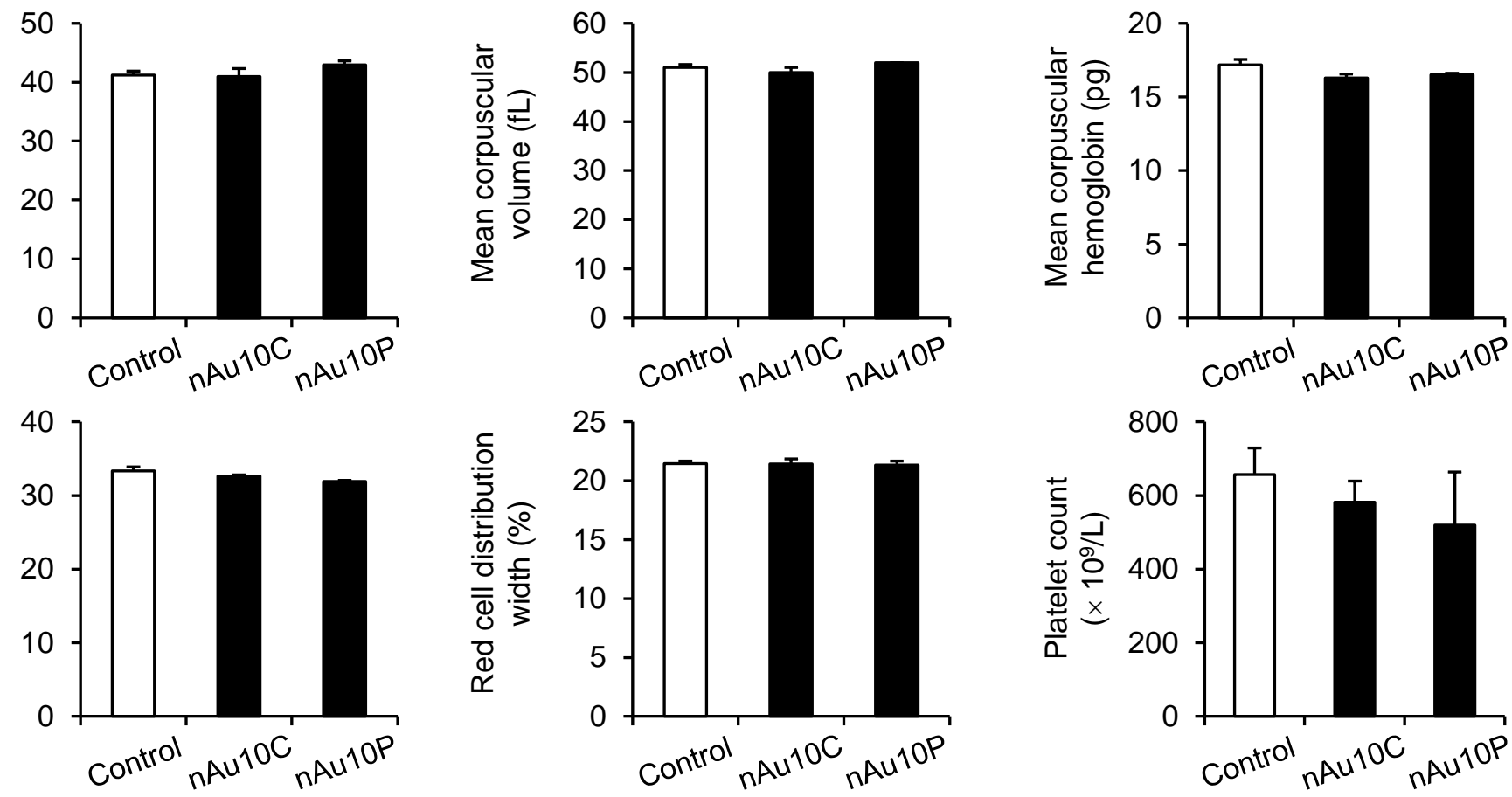

.
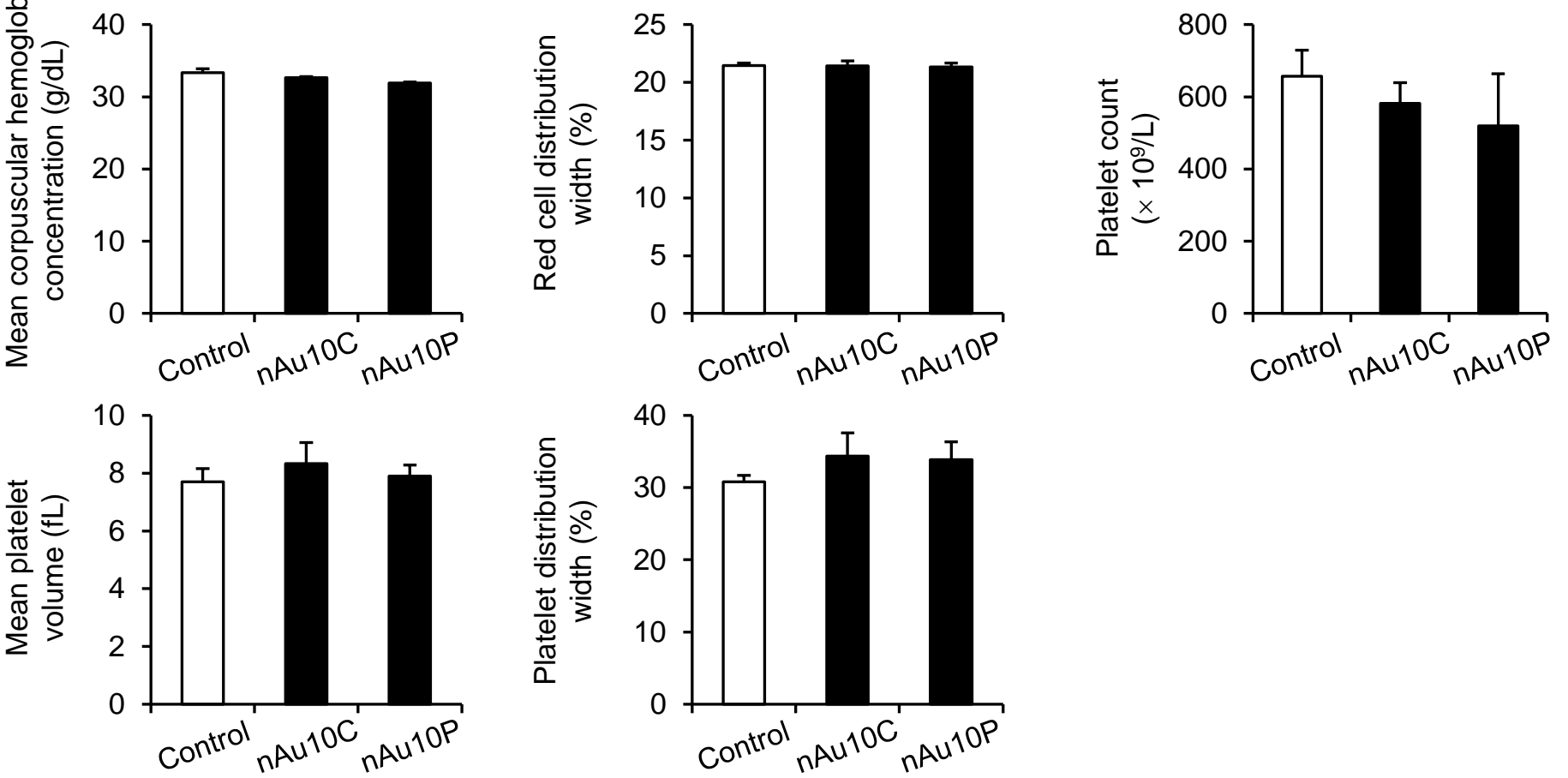

Supplementary Figure S13. Effects of a single intravenous injection of Au nanoparticles on hematology of dams. Lactating dams were intravenously injected with Au nanoparticles (4 mg/kg) or PBS containing mouse serum albumin (control). Hematologic indices of dams were measured at $12 \mathrm{~h}$ postadministration. Data are reported as means \pm SEMs $(n=3)$.

Supplementary Figure S13. Morishita et al. 

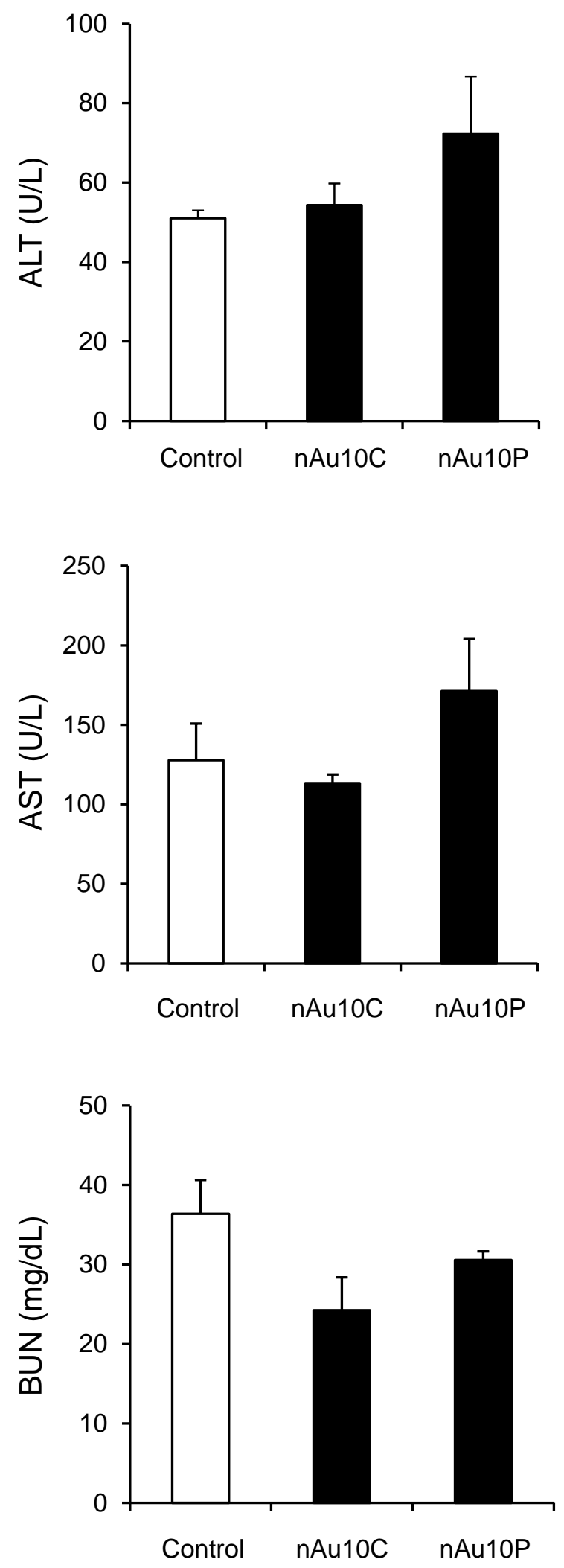

Supplementary Figure S14. Effects of a single intravenous injection of Au nanoparticles on blood chemistry of dams. Lactating dams were intravenously injected with Au nanoparticles $(4 \mathrm{mg} / \mathrm{kg})$ or PBS containing mouse serum albumin (control). Blood chemistry indices of dams were measured at $12 \mathrm{~h}$ postadministration: ALT, alanine aminotransferase; AST, aspartate aminotransferase; BUN, blood urea nitrogen. Data are reported as means $\pm \operatorname{SEMs}(n=3)$. 
a Control

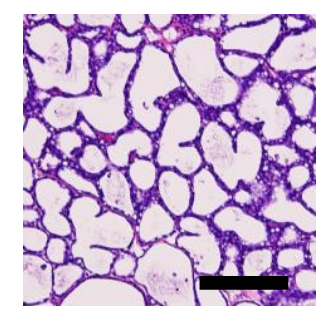

nAu10C

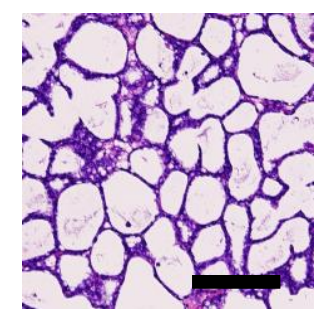

nAu10P

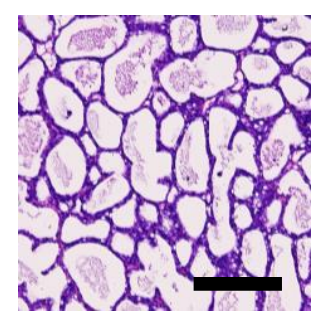

b

\begin{tabular}{cccc}
\hline & Control & nAu10C & nAu10P \\
\hline $\begin{array}{c}\text { Exfoliation of } \\
\text { breast duct cells }\end{array}$ & $1.0 \pm 0.3$ & $1.0 \pm 0$ & $0.8 \pm 0.2$ \\
$\begin{array}{c}\text { Calcification in } \\
\text { gland lumen }\end{array}$ & $0 \pm 0$ & $0 \pm 0$ & $0 \pm 0$ \\
\hline
\end{tabular}

C Control

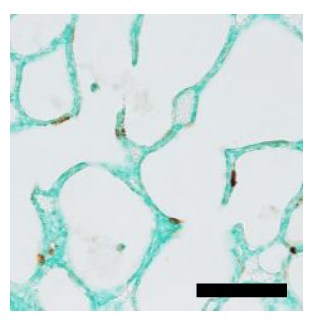

nAu10C

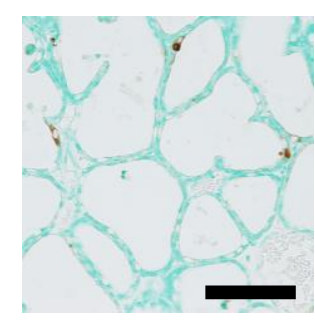

nAu10P
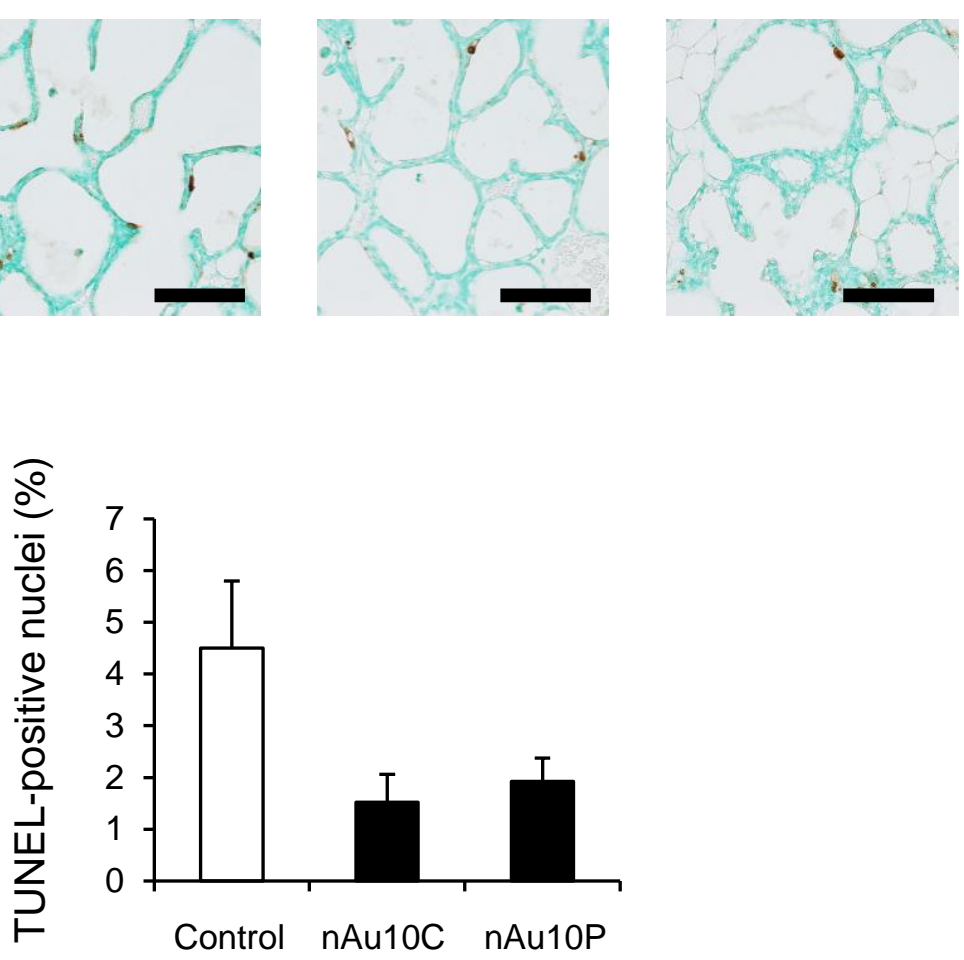

Supplementary Figure S15. Effects of a single intravenous injection of Au nanoparticles on mammary glands. Lactating dams were intravenously injected with Au nanoparticles (nAu10C or nAu10P, $4 \mathrm{mg} / \mathrm{kg}$ ) or PBS containing mouse serum albumin (control). a, At $12 \mathrm{~h}$ postadministration, sections of mammary glands were stained with hematoxylin and eosin (HE). Scale bars $=200 \mu \mathrm{m}$. b, Scores for pathological findings of mammary glands were evaluated in HE-stained sections. c, At $12 \mathrm{~h}$ postadministration, sections of mammary glands were stained with TUNEL. Scale bars $=100 \mu \mathrm{m}$. $d$, The apoptotic index was assessed by examining the TUNEL-stained sections and was quantitatively analyzed. Data were obtained from two independent experiments and are reported as means \pm SEM $(n=4-5)$. 
a Control

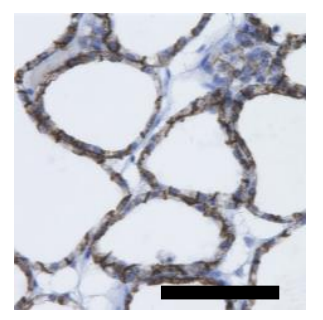

nAu10C

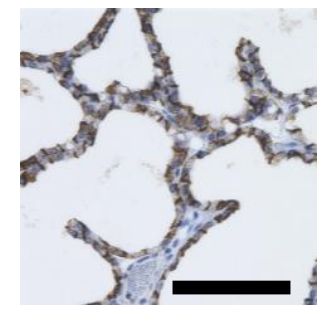

nAu10P

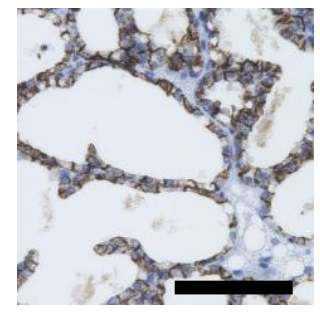

b

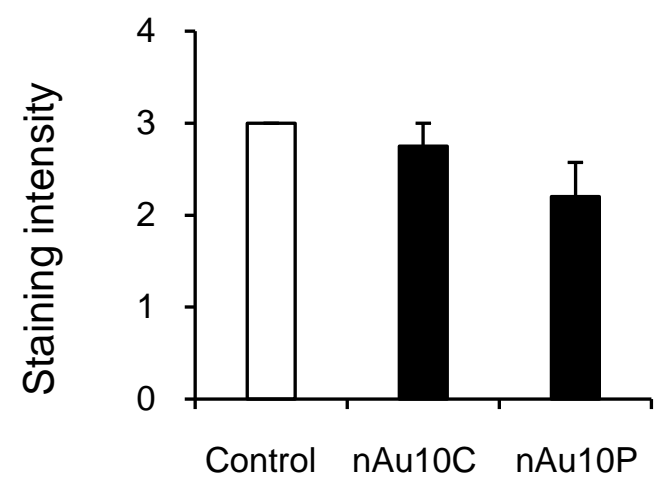

Supplementary Figure S16. Effects of a single intravenous injection of Au nanoparticles on claudin-3 in mammary glands. Lactating dams were intravenously injected with Au nanoparticles (nAu10C or nAu10P, 4 $\mathrm{mg} / \mathrm{kg}$ ) or PBS containing mouse serum albumin (control). a, At $12 \mathrm{~h}$ postadministration, sections of mammary glands were immunostained with an antibody to claudin-3. Scale bars $=100 \mu \mathrm{m}$. $\mathrm{b}$, The staining intensity of claudin-3 in mammary epithelial cells was evaluated in immunostained sections. Data were obtained from two independent experiments and are reported as means \pm SEMs $(n=4-5)$. 

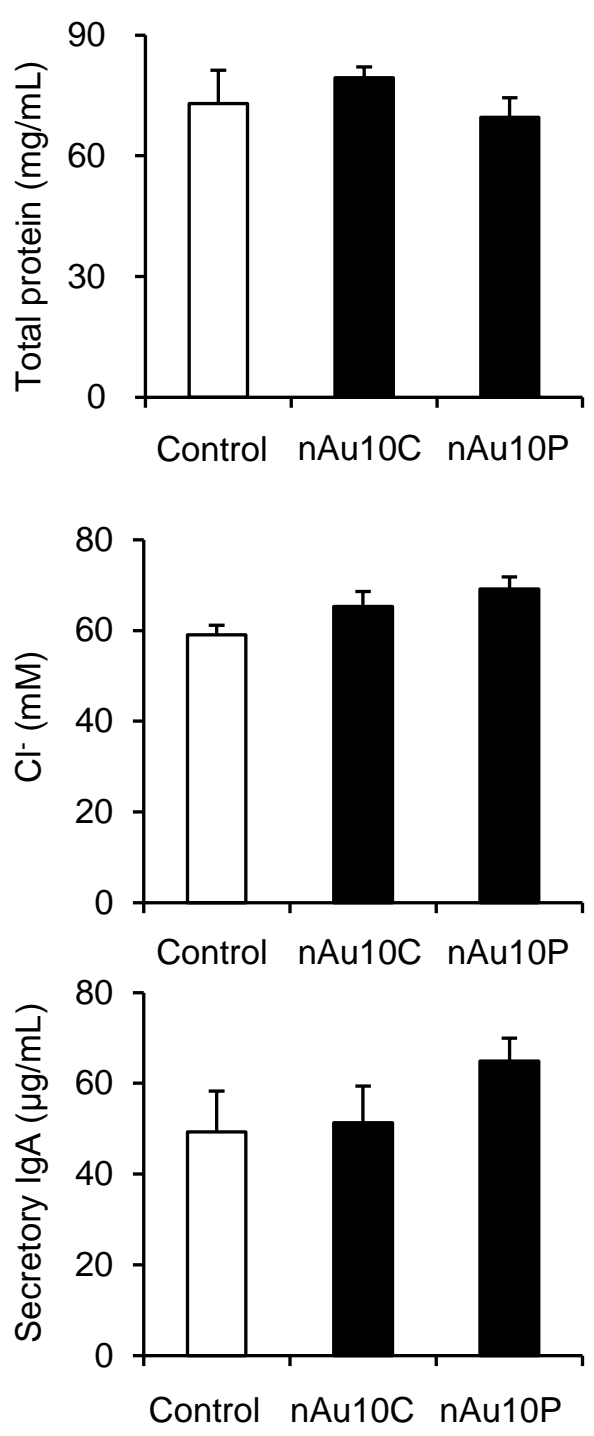
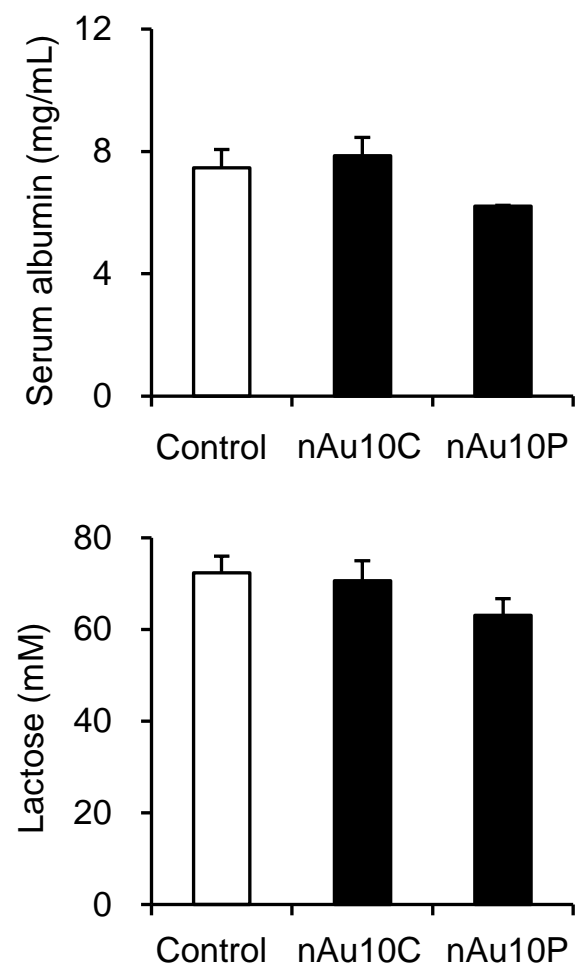

Supplementary Figure S17. Effects of a single intravenous injection of Au nanoparticles on milk composition. Lactating dams were intravenously injected with Au nanoparticles (nAu10C or nAu10P, $4 \mathrm{mg} / \mathrm{kg}$ ) or PBS containing mouse serum albumin (control). Total protein, serum albumin, $\mathrm{Cl}^{-}$, lactose, and secretory IgA concentrations in skim milk were measured at $12 \mathrm{~h}$ postadministration. Data are reported as means \pm SEM $(n=3-12)$. 


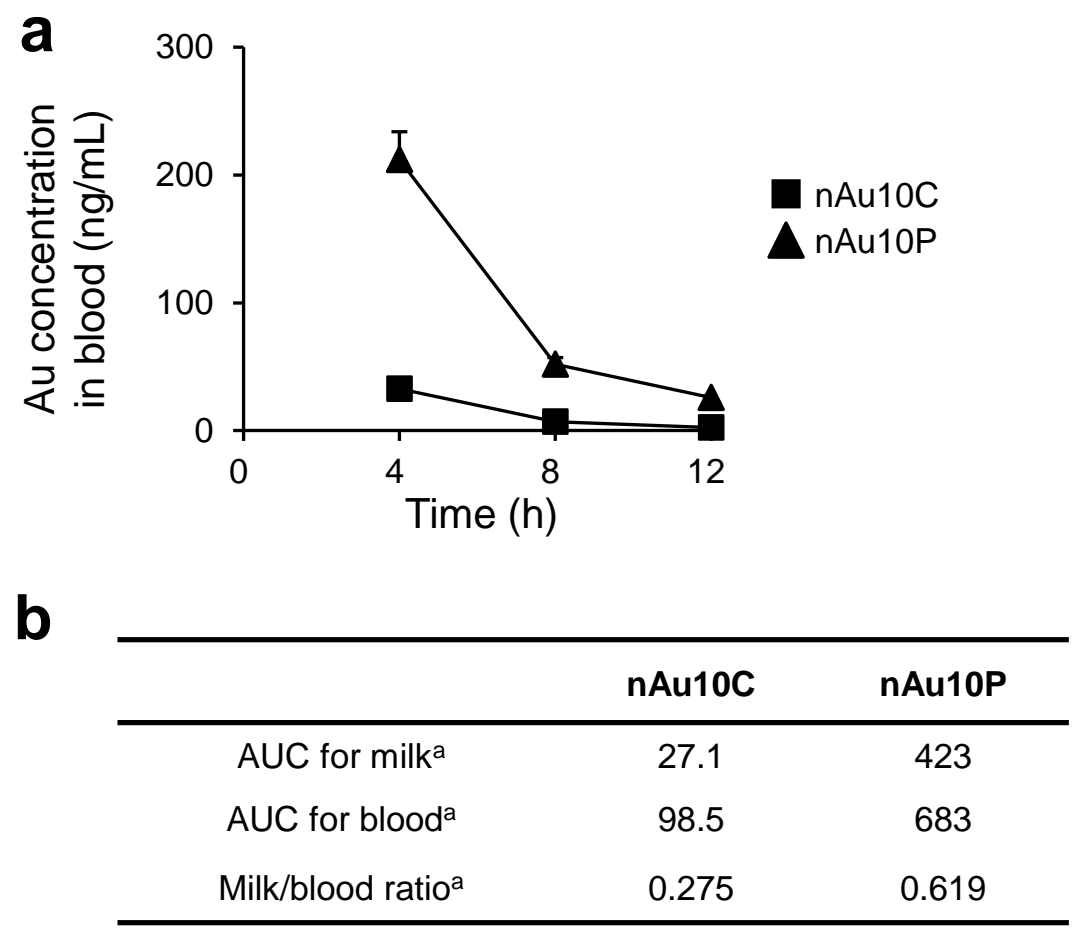

a AUC values were calculated for data points acquired during the period from 4 to $12 \mathrm{~h}$.

Supplementary Figure S18. Distribution of Au nanoparticles after a single intravenous injection to dams. Lactating dams were intravenously injected with nAu10C or nAu10P $(4 \mathrm{mg} / \mathrm{kg})$. a, Au concentrations in blood were measured. b, The AUC for milk, the AUC for blood, and the milk/blood ratio of Au were calculated from the data in a and Figure 1e. Data are reported as means \pm SEMs $(n=3-5)$. 

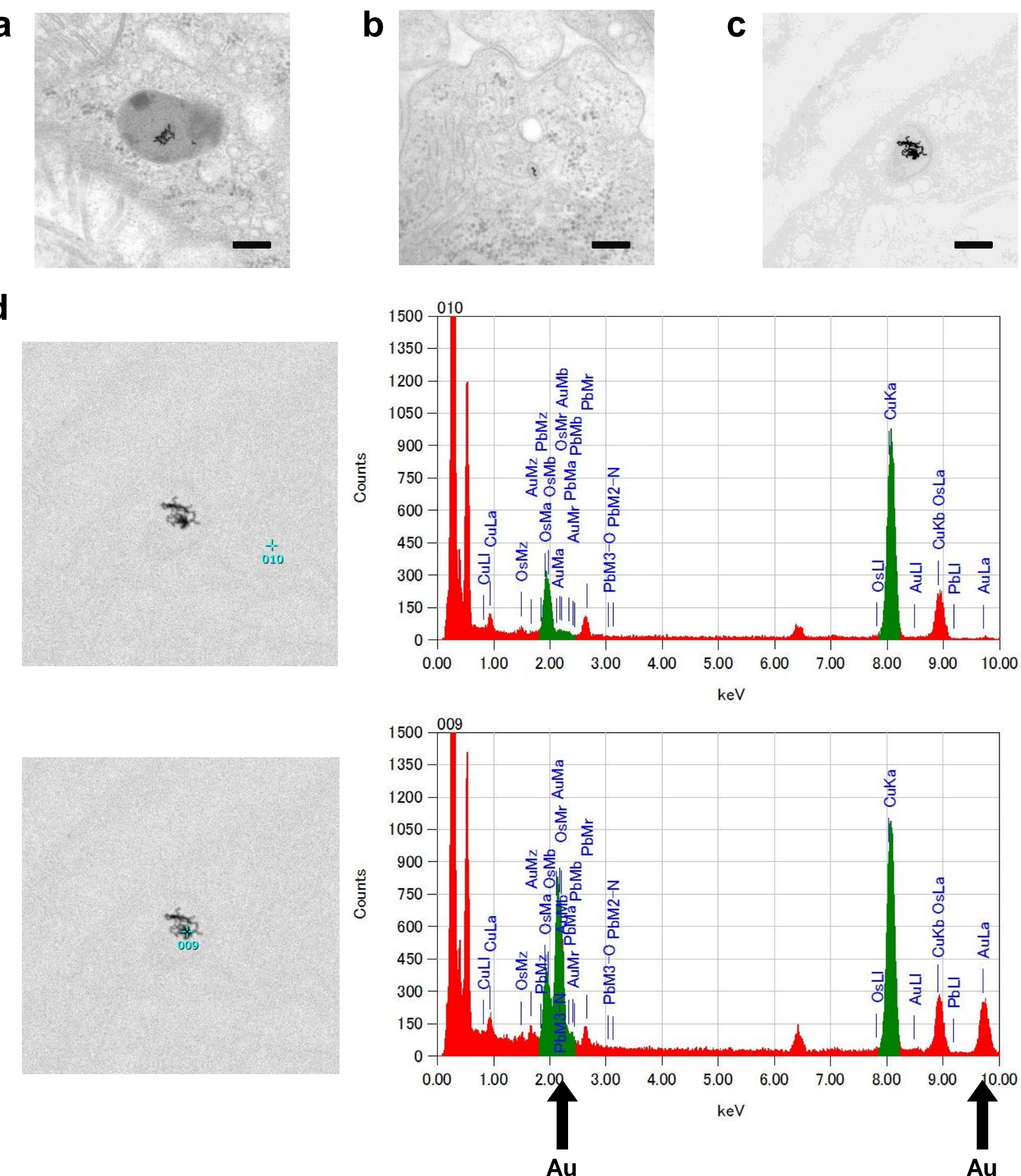

Supplementary Figure S19. TEM analysis of nAu10P in mammary glands. Lactating dams were intravenously injected with nAu10P (4 mg/kg). At $12 \mathrm{~h}$ postadministration, mammary glands were observed by TEM. $\mathrm{nAu10P}$ were found in lysosomes (a) and intracellular vesicles (b) of vascular endothelial cells, and lysosomes of lymphocytes localized in the vascular lumen (c). Scale bars $=200 \mathrm{~nm}$. d, The presence of Au was confirmed by energy dispersive X-ray spectroscopy analysis for the TEM image in c. Arrows indicate clear signals of Au.

\section{Supplementary Figure S19. Morishita et al}



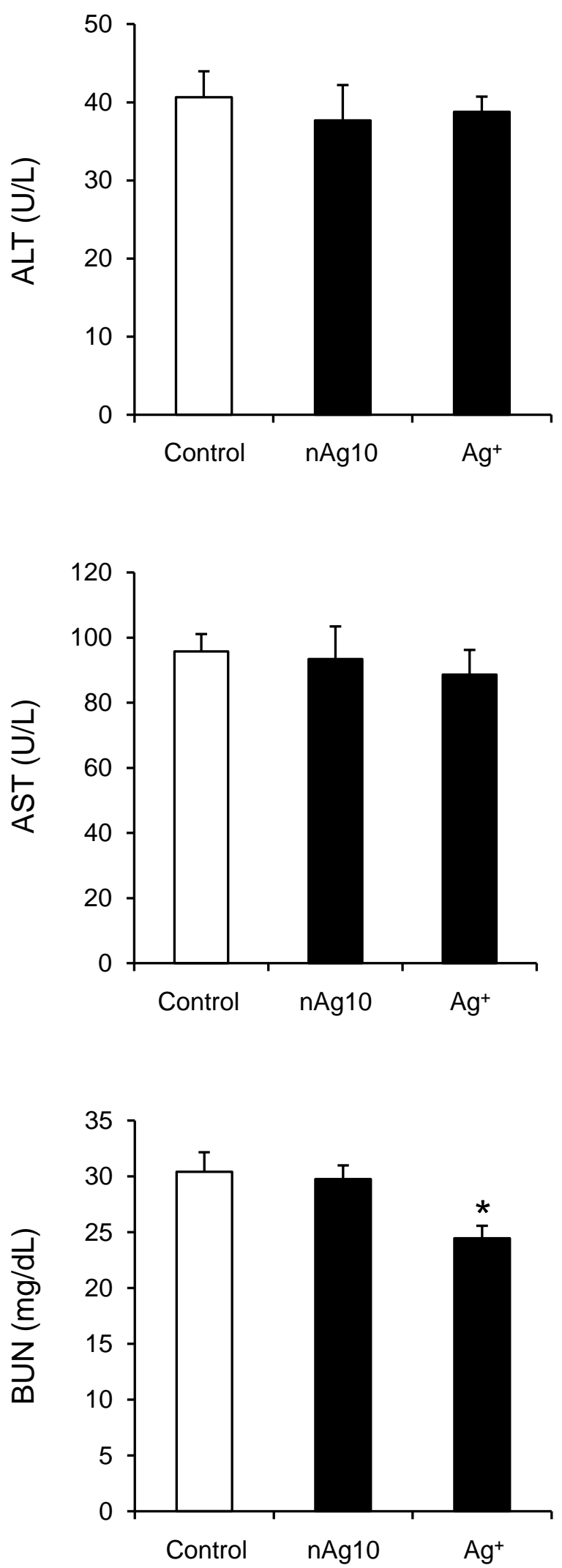

Supplementary Figure S21. Effects of a single oral dose of $\mathrm{nAg10}$ or $\mathrm{Ag}^{+}$on blood chemistry of dams. $\mathrm{Ag}$ nanoparticles $(10 \mathrm{mg} / \mathrm{kg}), \mathrm{Ag}^{+}(10 \mathrm{mg} / \mathrm{kg})$, or water (control) was orally administered to lactating dams. Blood chemistry indices of dams were measured at $12 \mathrm{~h}$ postadministration: ALT, alanine aminotransferase; AST, aspartate aminotransferase; BUN, blood urea nitrogen. Data were obtained from three independent experiments and are reported as means \pm SEMs $(n=8-9) .{ }^{*} P<0.05$ vs control group. 

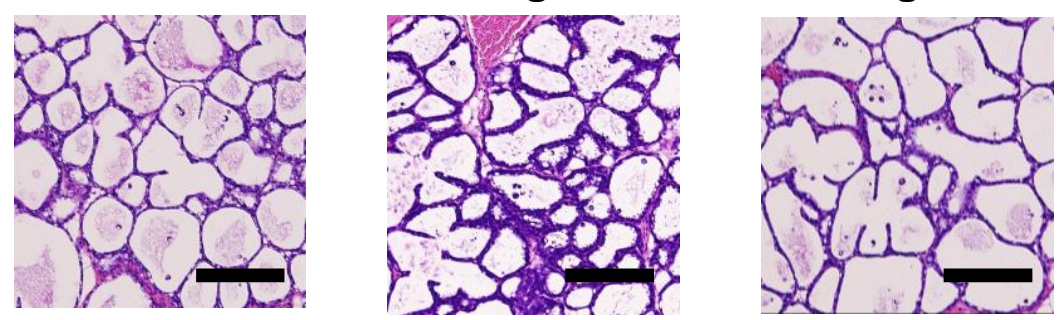

b

\begin{tabular}{cccc}
\hline & Control & nAg10 & Ag $^{+}$ \\
\hline $\begin{array}{c}\text { Exfoliation of } \\
\text { breast duct cells } \\
\begin{array}{c}\text { Calcification in } \\
\text { gland lumen }\end{array}\end{array} 1.0 \pm 0$ & $1.0 \pm 0$ & $1.0 \pm 0$ \\
\hline
\end{tabular}

C

Control

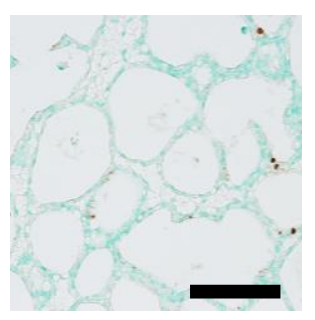

nAg10

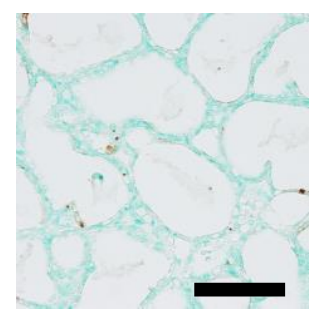

$\mathrm{Ag}^{+}$

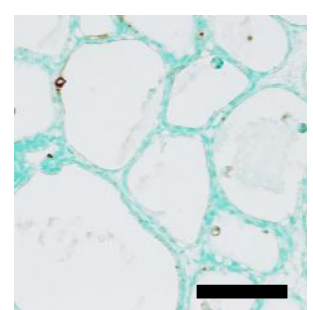

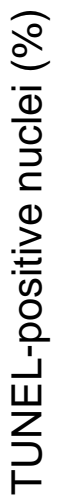

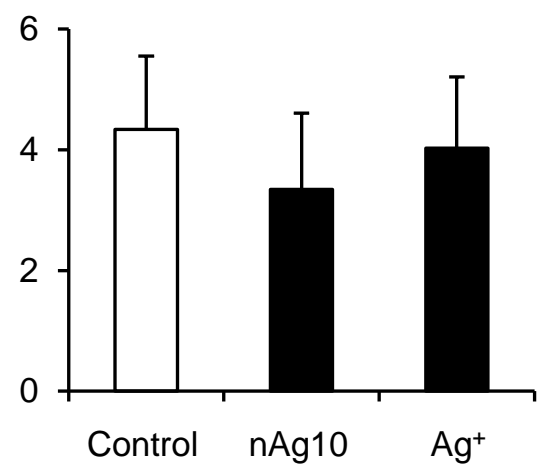

Supplementary Figure S22. Effects of a single oral dose of $\mathrm{nAg} 10$ or $\mathrm{Ag}^{+}$on mammary glands. $\mathrm{Ag}$ nanoparticles $(10 \mathrm{mg} / \mathrm{kg}), \mathrm{Ag}^{+}(10 \mathrm{mg} / \mathrm{kg})$, or water (control) was orally administered to lactating dams. a, At $12 \mathrm{~h}$ postadministration, sections of mammary glands were stained with hematoxylin and eosin (HE). Scale bars $=\mathbf{2 0 0} \mu \mathrm{m}$. b, Scores for pathological findings of mammary glands were evaluated in HEstained sections. c, At $12 \mathrm{~h}$ postadministration, sections of mammary glands were stained with TUNEL. Scale bars $=100 \mu \mathrm{m}$. d, The apoptotic index was assessed by examining the TUNEL-stained sections and was quantitatively analyzed. Data were obtained from two independent experiments and are reported as means \pm SEMs $(n=4-5)$. 
a

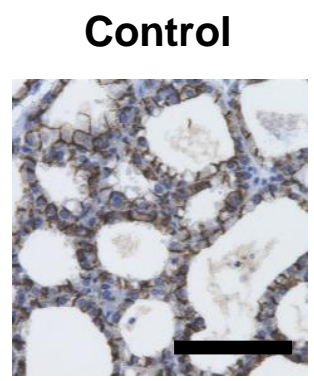

$\mathrm{Ag}^{+}$
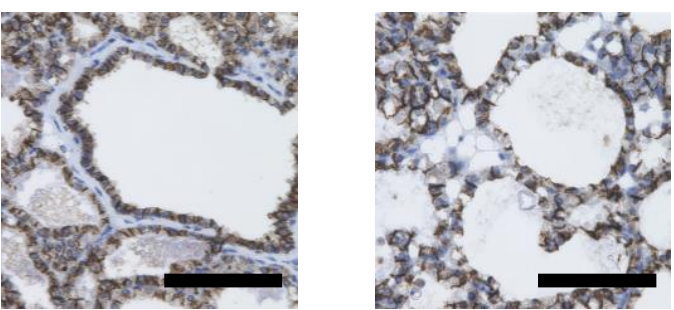

b

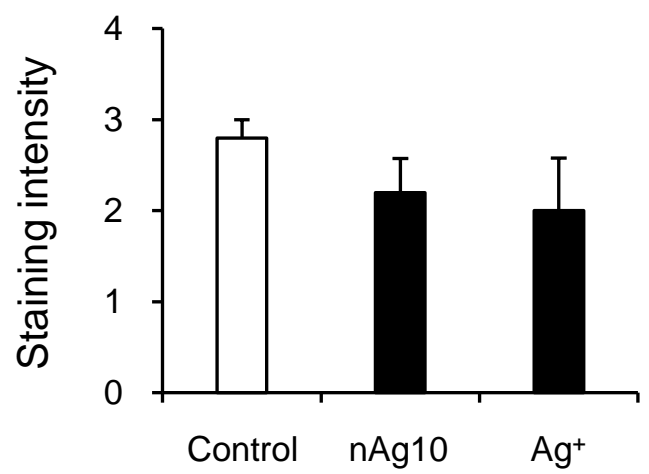

Supplementary Figure S23. Effects of a single oral dose of $\mathrm{nAg} 10$ or $\mathrm{Ag}^{+}$on claudin-3 in mammary glands. $\mathrm{Ag}$ nanoparticles $(10 \mathrm{mg} / \mathrm{kg}), \mathrm{Ag}^{+}(10 \mathrm{mg} / \mathrm{kg})$, or water (control) was orally administered to lactating dams. a, At 12 h postadministration, sections of mammary glands were immunostained with an antibody to claudin-3. Scale bars $=100 \mu \mathrm{m}$. b. The staining intensity of claudin-3 in mammary epithelial cells was evaluated in immunostained sections. Data were obtained from two independent experiments and are reported as means $\pm \operatorname{SEMs}(n=4-5)$. 

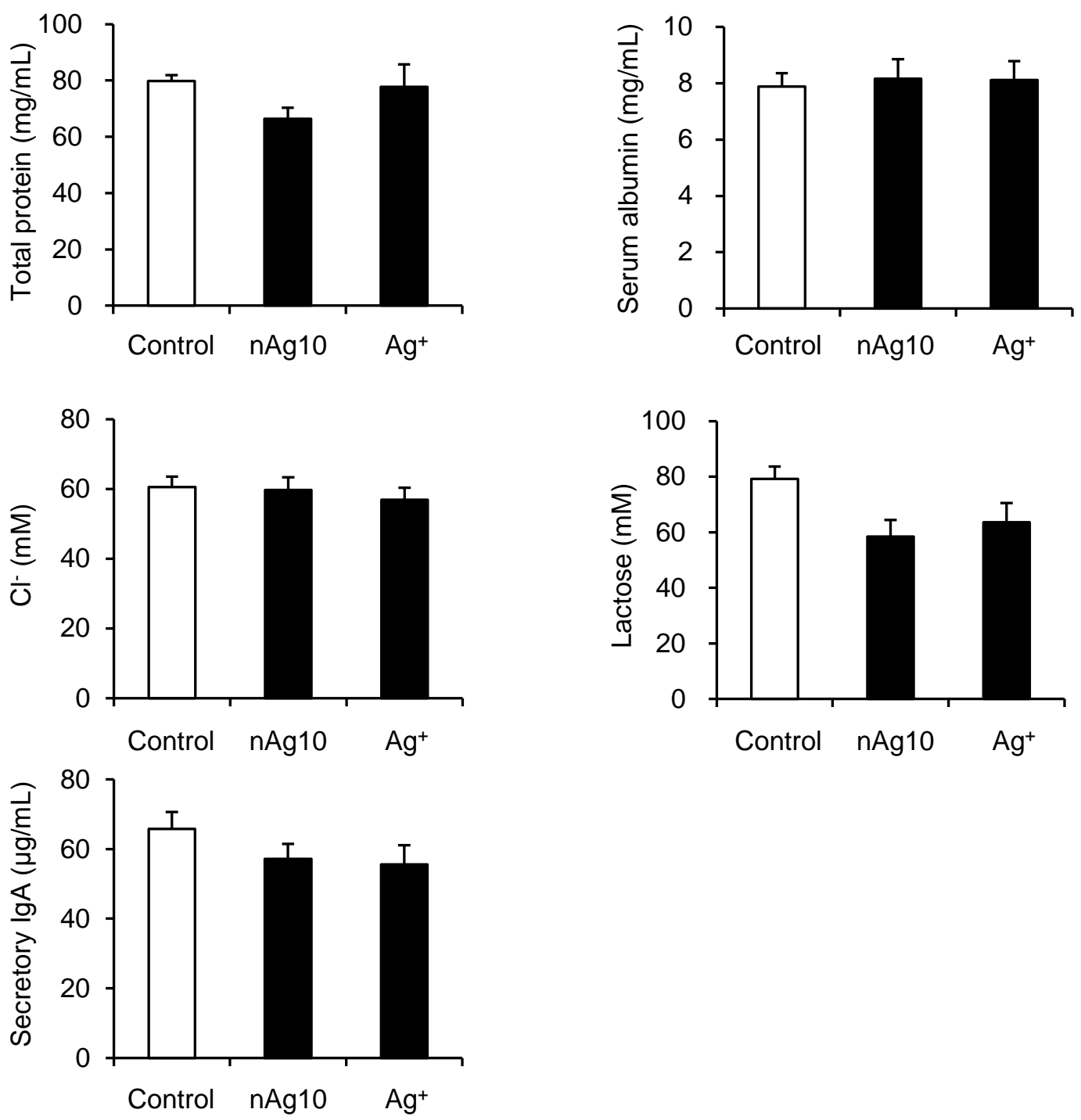

Supplementary Figure S24. Effects of a single oral dose of $\mathrm{nAg} 10$ or $\mathrm{Ag}^{+}$on milk composition. $\mathbf{A g}$ nanoparticles $(10 \mathrm{mg} / \mathrm{kg}), \mathrm{Ag}^{+}(10 \mathrm{mg} / \mathrm{kg})$, or water (control) was orally administered to lactating dams. Total protein, serum albumin, $\mathrm{Cl}^{-}$, lactose, and secretory IgA concentrations in skim milk were measured at $12 \mathrm{~h}$ postadministration. Data were obtained from three independent experiments and are reported as means \pm SEMs $(n=3-9)$. 


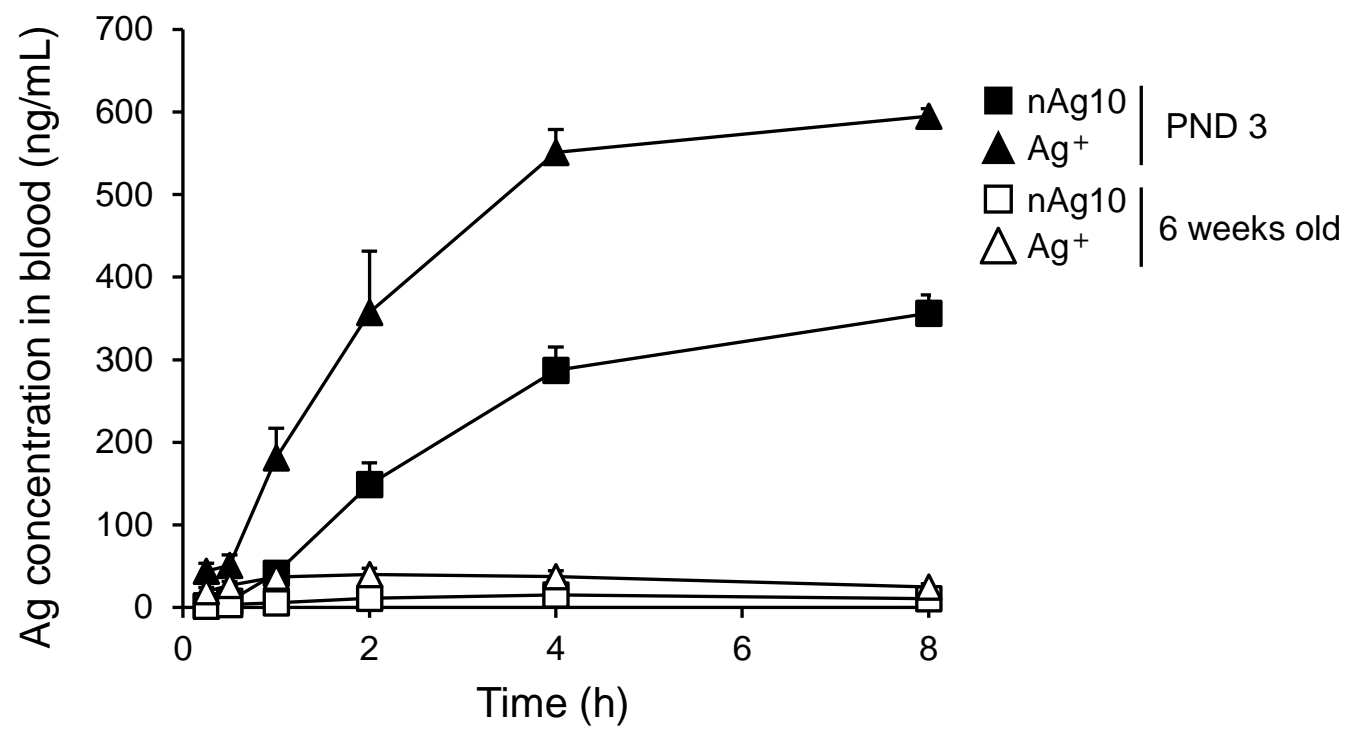

Supplementary Figure S25. Ag concentrations in blood of pups and adult mice after administration of a single oral dose of $\mathrm{nAg} 10$ or $\mathrm{Ag}^{+} . \mathrm{nAg} 10(2.5 \mathrm{mg} / \mathrm{kg})$ or $\mathrm{Ag}^{+}(2.5 \mathrm{mg} / \mathrm{kg})$ was orally administered to pups (on PND 3) and adult mice (6 weeks old). Ag concentrations in blood were measured. Data are reported as means \pm SEMs $(n=4-5)$. 

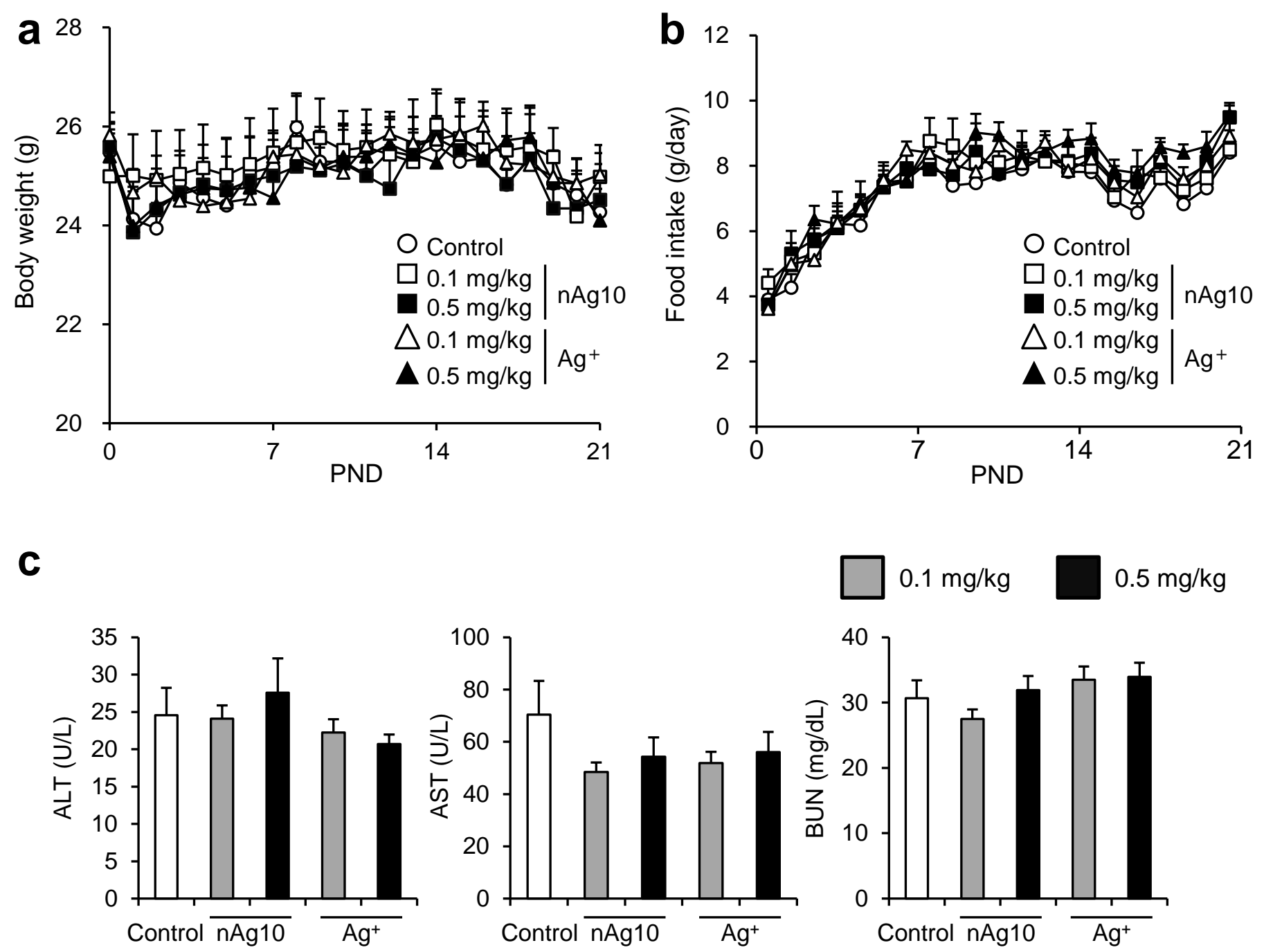

Supplementary Figure S26. Effects of consecutive daily oral administration of $\mathrm{nAg} 10$ or $\mathrm{Ag}^{+}$on dams. $\mathrm{nAg} 10(0.1$ or $0.5 \mathrm{mg} / \mathrm{kg}), \mathrm{Ag}^{+}(0.1$ or $0.5 \mathrm{mg} / \mathrm{kg})$, or water (control) was orally administered to lactating dams daily from PND 0 to 20. Body weights (a) and daily food intakes (b) of dams were measured from PND 0 to 21, and blood chemistry indices of dams (c) were measured on PND 21: ALT, alanine aminotransferase; AST, aspartate aminotransferase; BUN, blood urea nitrogen. Data are reported as means \pm SEMs (a,b: $n=4-10 ; c: n=8-10)$. 


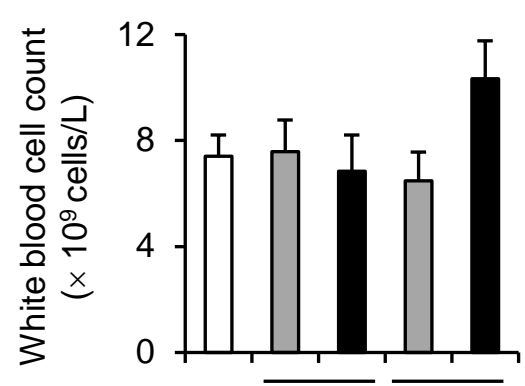

Control $\overline{\mathrm{nAg} 10} \overline{\mathrm{Ag}^{+}}$

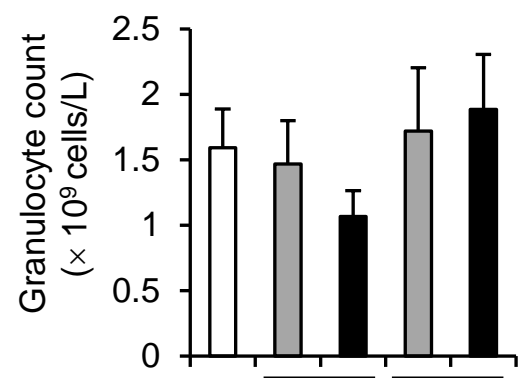

Control $\overline{\mathrm{nAg} 10} \overline{\mathrm{Ag}^{+}}$

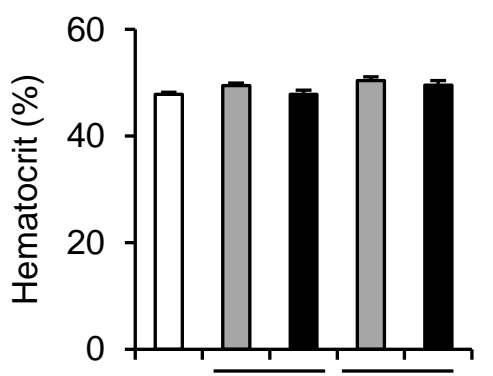

.

Control $\overline{\mathrm{nAg} 10} \overline{\mathrm{Ag}^{+}}$

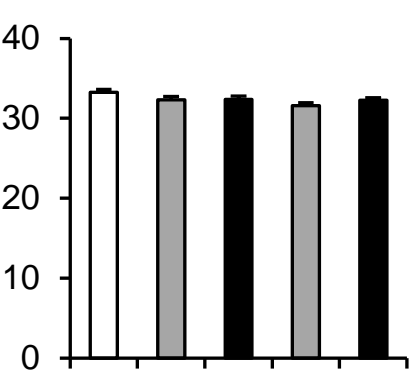

Control $\overline{\mathrm{nAg} 10} \overline{\mathrm{Ag}^{+}}$

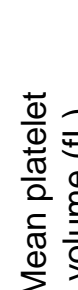

10
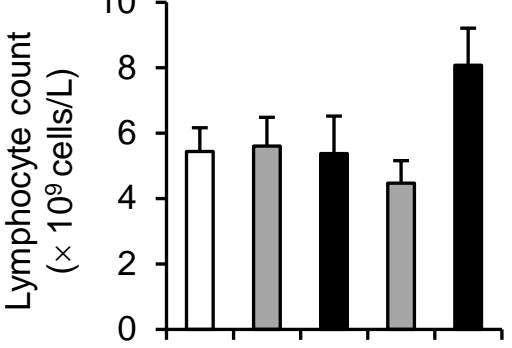

Control $\overline{\mathrm{nAg} 10} \overline{\mathrm{Ag}^{+}}$
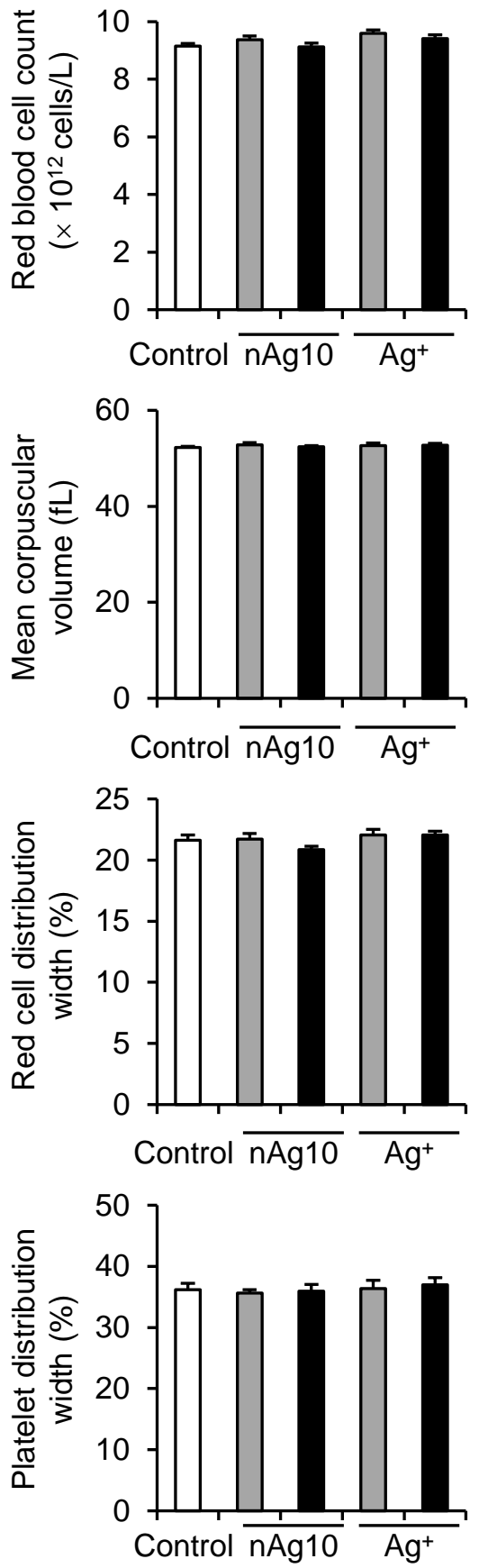
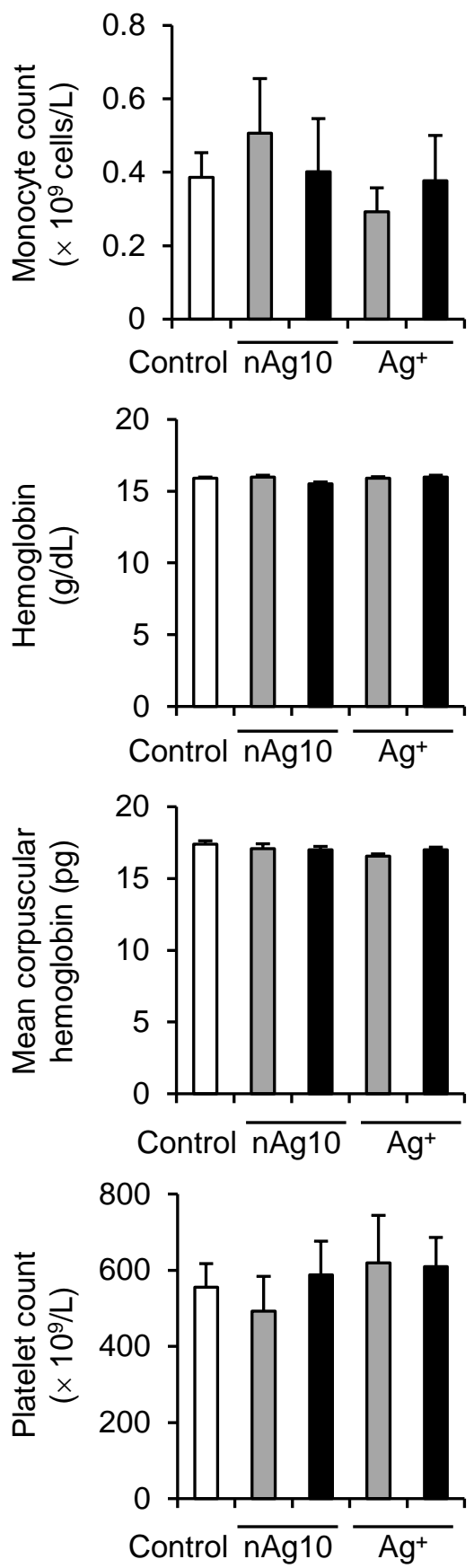

Control $\overline{\mathrm{nAg} 10} \overline{\mathrm{Ag}^{+}}$

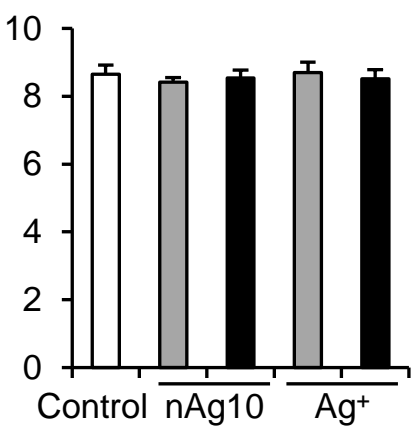

Supplementary Figure S27. Effects of consecutive daily oral administration of $\mathrm{nAg} 10$ or $\mathrm{Ag}^{+}$on hematology of dams. $\mathrm{nAg} 10(0.1$ or $0.5 \mathrm{mg} / \mathrm{kg}), \mathrm{Ag}^{+}(0.1$ or $0.5 \mathrm{mg} / \mathrm{kg}$ ), or water (control) was orally administered to lactating dams daily from PND 0 to 20. Hematologic indices of dams were measured on PND 21. Data are reported as means \pm SEMs $(n=8-10)$.

Supplementary Figure S27. Morishita et al. 


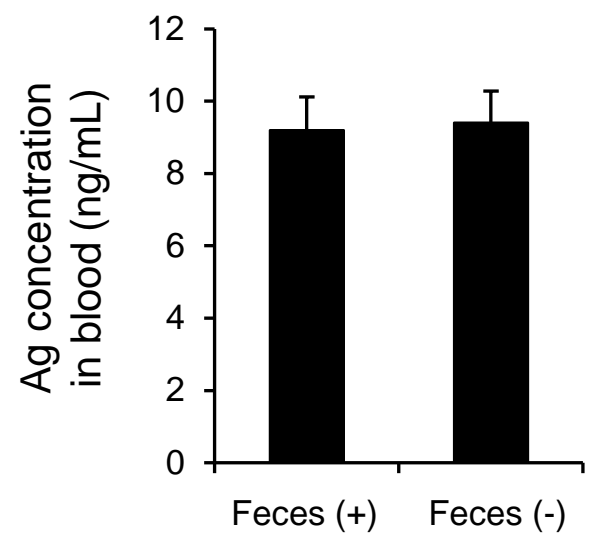

Supplementary Figure S28. Effects of exposure to maternal feces on the Ag concentration in pups' blood. nAg10 (10 mg/kg) was orally administered to lactating dams on PND 3, and the dams were housed with their pups in a conventional cage (feces (+) group) or a metabolic cage (feces (-) group). The Ag concentrations in the blood of pups that were breast-fed by the dams were measured at $24 \mathrm{~h}$ postadministration. Data were obtained from two independent experiments and are reported as means \pm SEMs $(n=44-45)$. 


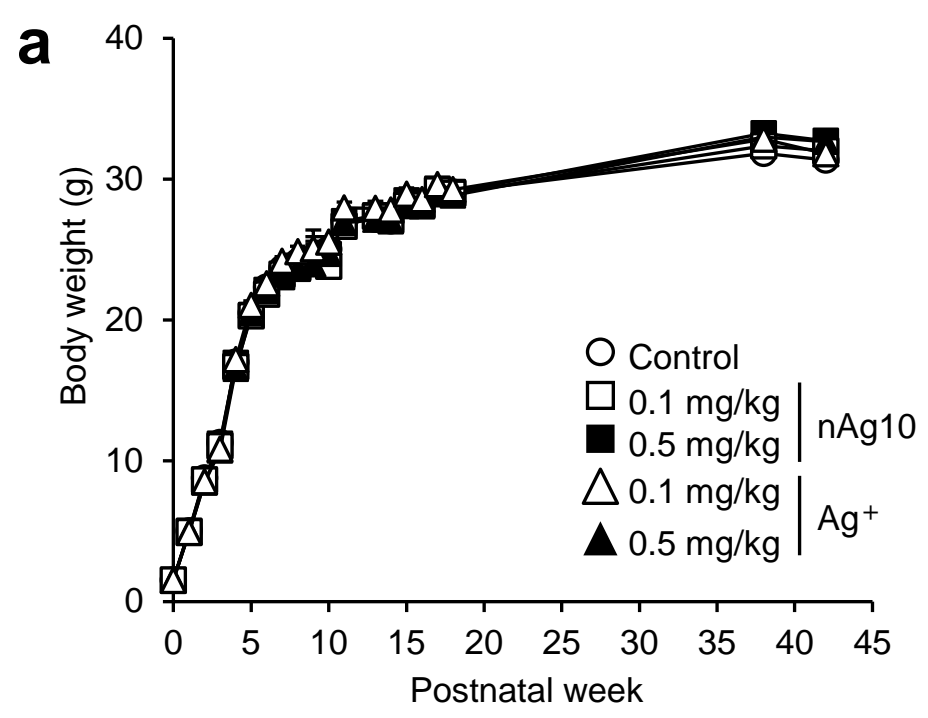

b
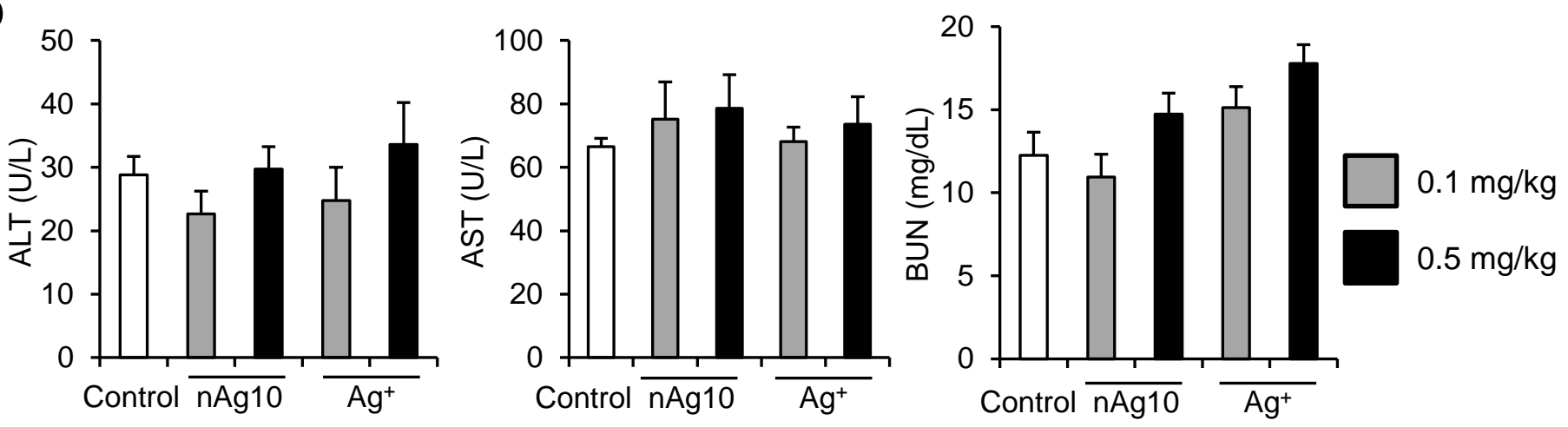

Supplementary Figure S29. Body weights and blood chemistry indices of pups breast-fed by dams that received oral $\mathrm{nAg} 10$ or $\mathrm{Ag}^{+}$daily from PND 0 to 20 . $\mathrm{nAg} 10$ (0.1 or $\left.0.5 \mathrm{mg} / \mathrm{kg}\right), \mathrm{Ag}^{+}(0.1$ or $0.5 \mathrm{mg} / \mathrm{kg})$, or water (control) was orally administered to lactating dams daily from PND 0 to 20 . The body weights of pups (a) were measured from postnatal week 0 to postnatal week 42 . After postnatal week 4 , data were collected only for male pups. Blood chemistry indices of female pups (b) were measured on PND 21: ALT, alanine aminotransferase; AST, aspartate aminotransferase; BUN, blood urea nitrogen. Data are reported as means \pm SEMs (a: $n=14-62 ; b: n=6-16)$. 

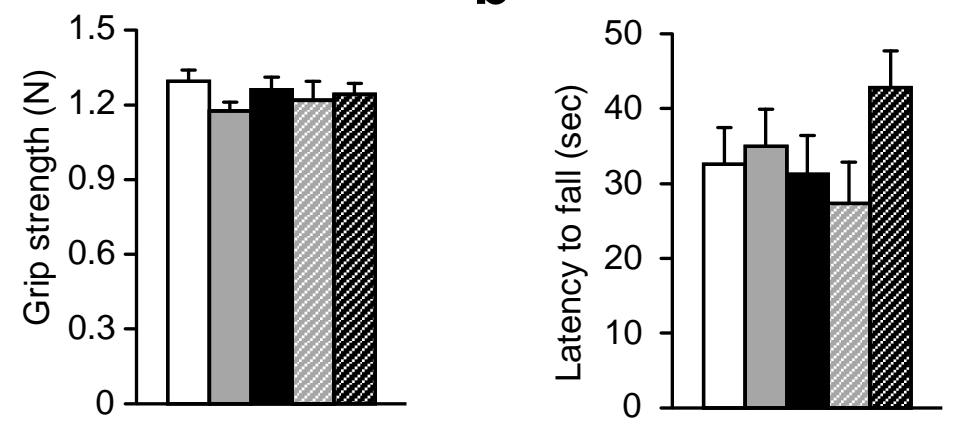

\begin{tabular}{|c|c|c|c|}
\hline \multicolumn{2}{|c|}{$\begin{array}{l}\text { Bar graph } \\
\square \text { Control }\end{array}$} & \multicolumn{2}{|c|}{ Line graph } \\
\hline $\begin{array}{r}\square 0.1 \mathrm{mg} / \mathrm{kg} \\
0.5 \mathrm{mg} / \mathrm{kg}\end{array}$ & nAg10 & $\begin{array}{r}\square 0.1 \mathrm{mg} / \mathrm{kg} \\
0.5 \mathrm{mg} / \mathrm{kg}\end{array}$ & $\mathrm{nAg} 10$ \\
\hline $\begin{array}{l}0.1 \mathrm{mg} / \mathrm{kg} \\
0.5 \mathrm{mg} / \mathrm{kg}\end{array}$ & $\mathrm{Ag}^{+}$ & $\begin{array}{l}\triangle 0.1 \mathrm{mg} / \mathrm{kg} \\
\triangle 0.5 \mathrm{mg} / \mathrm{kg}\end{array}$ & $\mathrm{Ag}^{+}$ \\
\hline
\end{tabular}

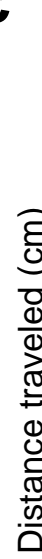
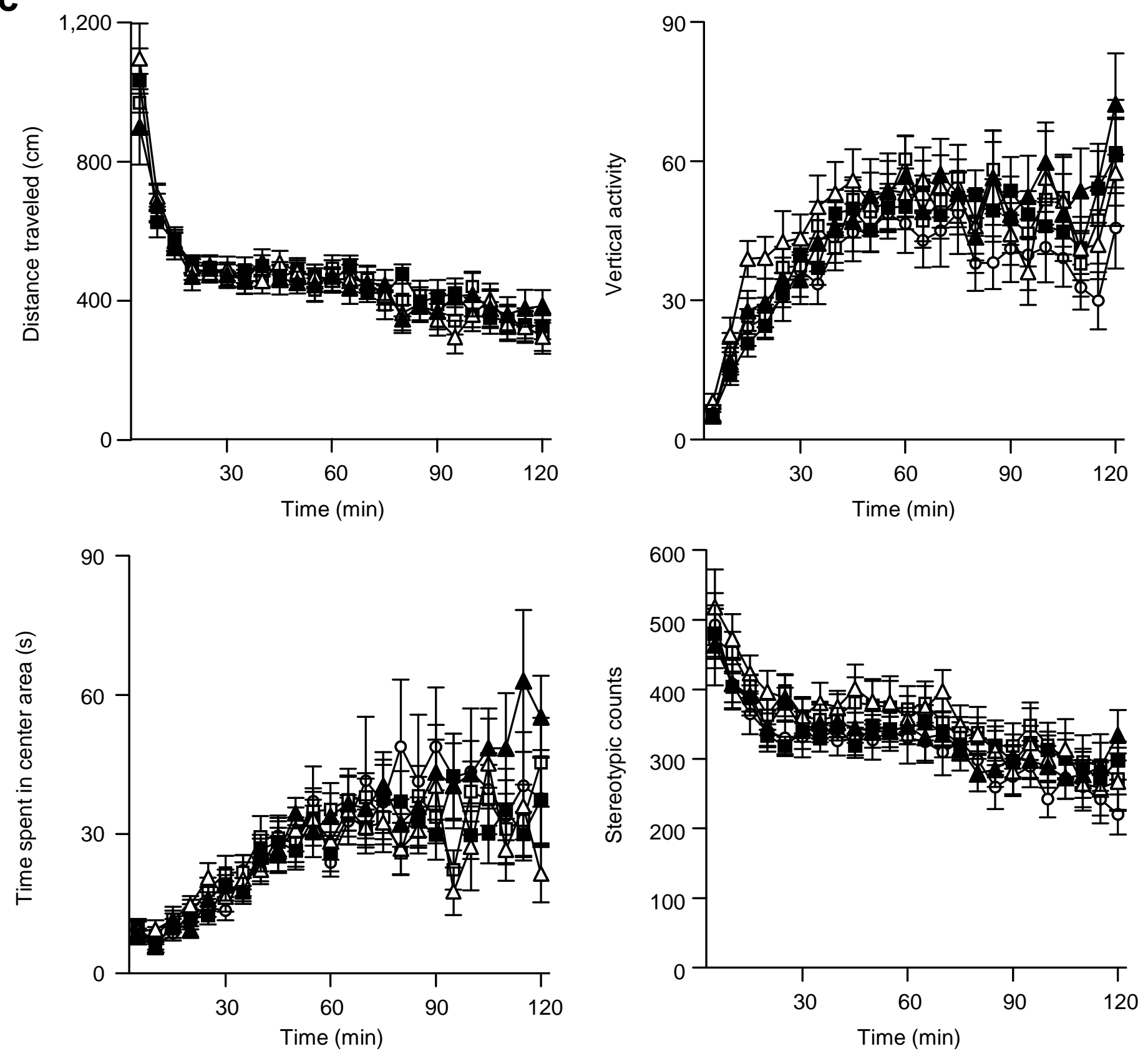

Supplementary Figure S32. Behavioral analyses of male offspring breast-fed by dams that received oral nAg10 or $\mathrm{Ag}^{+}$daily from PND 0 to 20, Part 1. Graphs of measured indices for a, grip strength test; $b$, wire hang test; c, open field test. Data are reported as means \pm SEMs $(n=16-20)$.

Supplementary Figure S32. Morishita et al. 

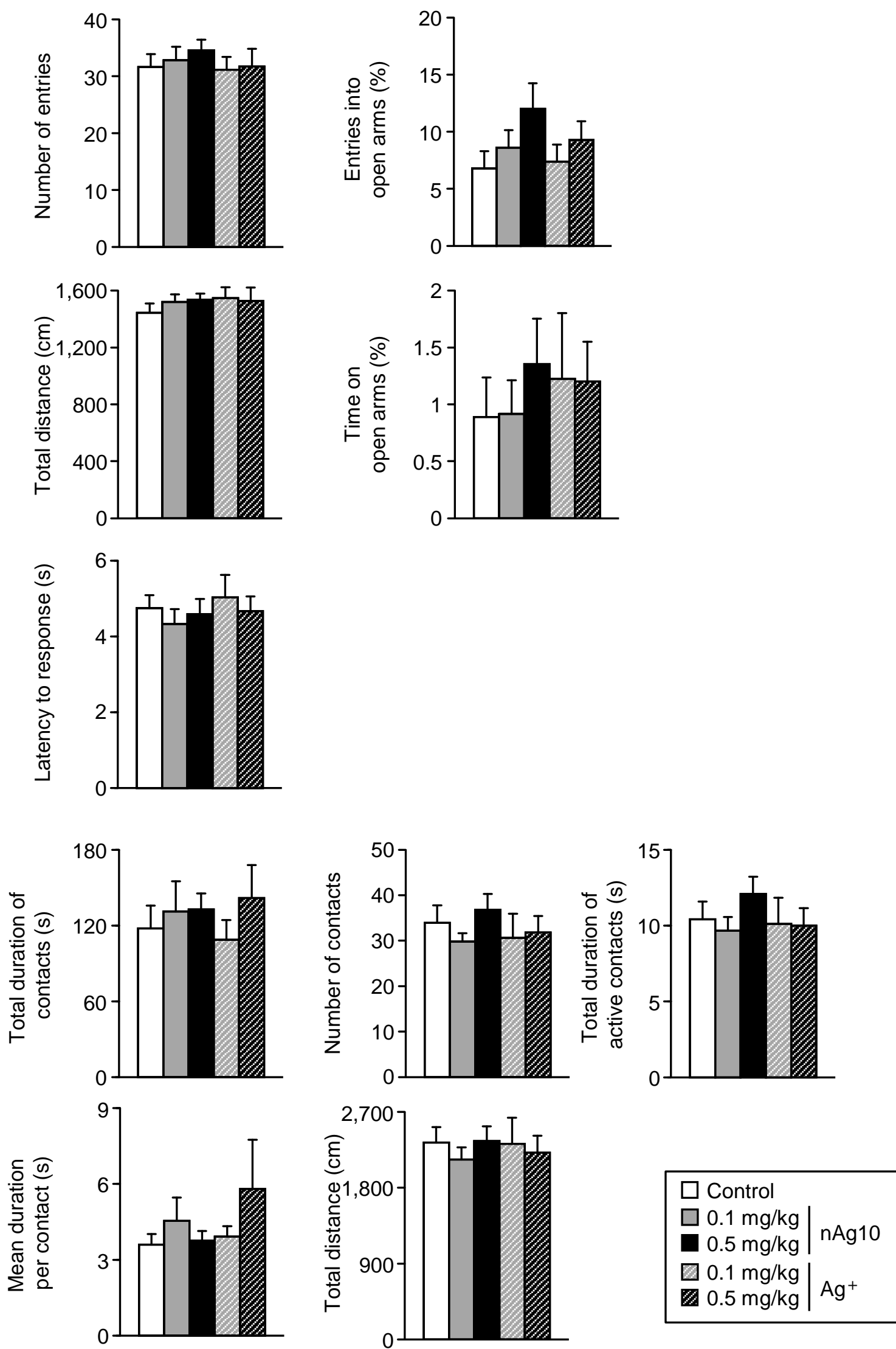

Supplementary Figure S33. Behavioral analyses of male offspring breast-fed by dams that received oral nAg10 or $\mathrm{Ag}^{+}$daily from PND 0 to 20, Part 2. Graphs of measured indices for a, elevated plus maze test; b, hot plate test; c, social interaction test. Data are reported as means \pm SEMs (social interaction test: $n$ = 8-10 pairs; others: $n=16-20$ ). 


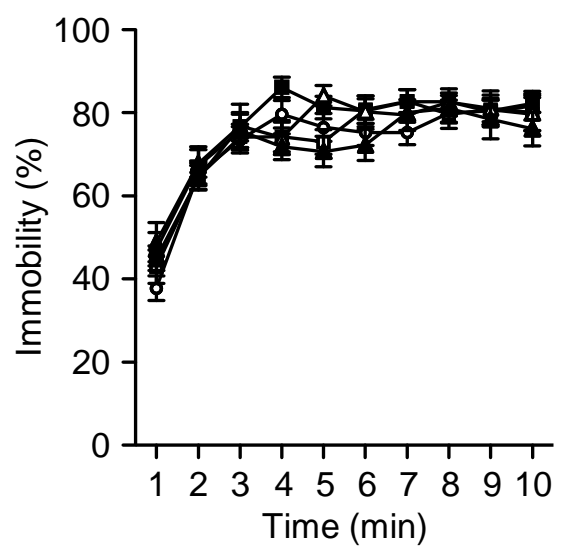

\begin{tabular}{|l|l|}
\hline O Control \\
$\square 0.1 \mathrm{mg} / \mathrm{kg}$ & \\
$0.5 \mathrm{mg} / \mathrm{kg}$ & $\mathrm{nAg} 10$ \\
$\triangle 0.1 \mathrm{mg} / \mathrm{kg}$ & $\mathrm{Ag}^{+}$ \\
$\Delta$ & $0.5 \mathrm{mg} / \mathrm{kg}$
\end{tabular}

b
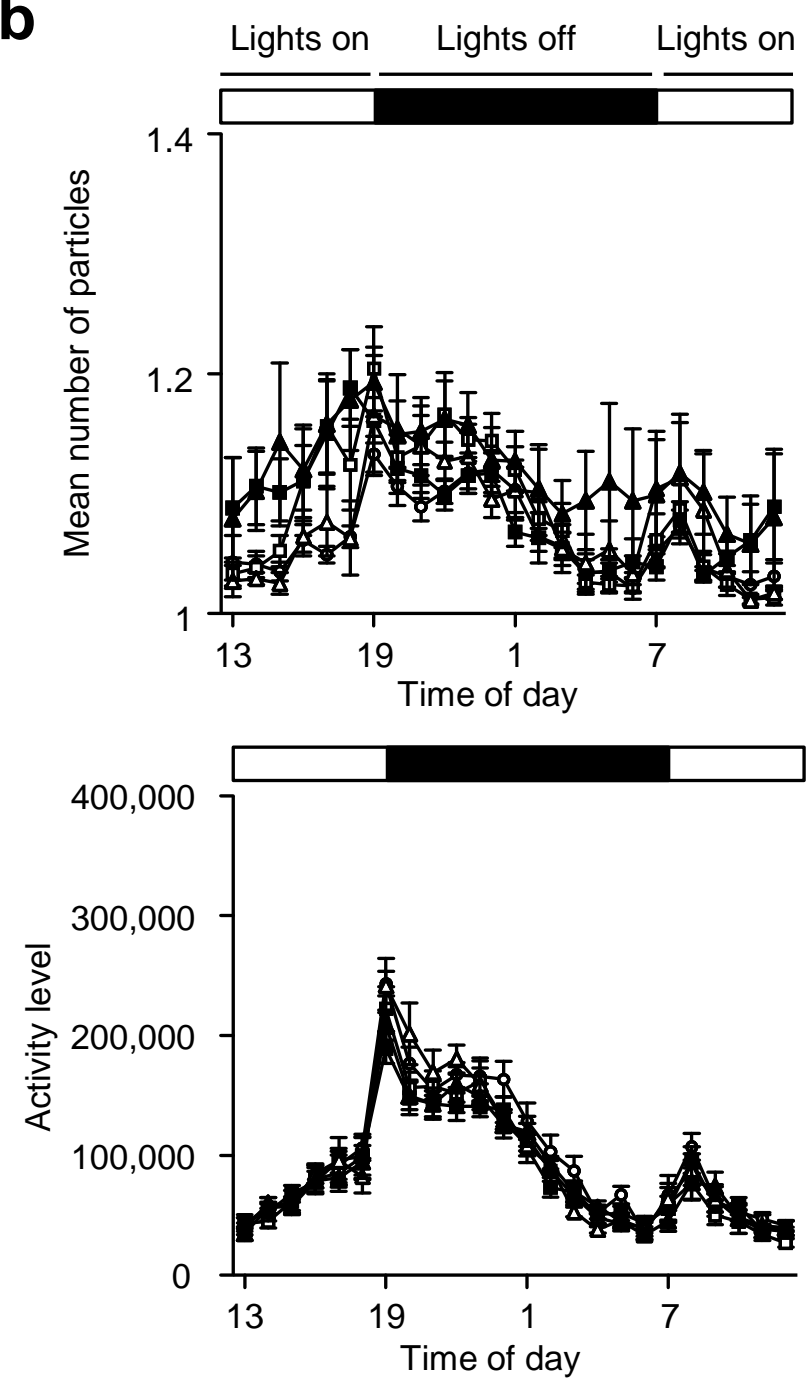

Supplementary Figure S35. Behavioral analyses of male offspring breast-fed by dams that received oral nAg10 or $\mathrm{Ag}^{+}$daily from PND 0 to 20, Part 4. Graphs of measured indices for a, tail suspension test; $b$, home cage monitoring. Data are reported as means \pm SEMs (tail suspension test: $n=16-20$; home cage monitoring: $n=7-10$ pairs).

\section{Supplementary Figure S35. Morishita et al.}




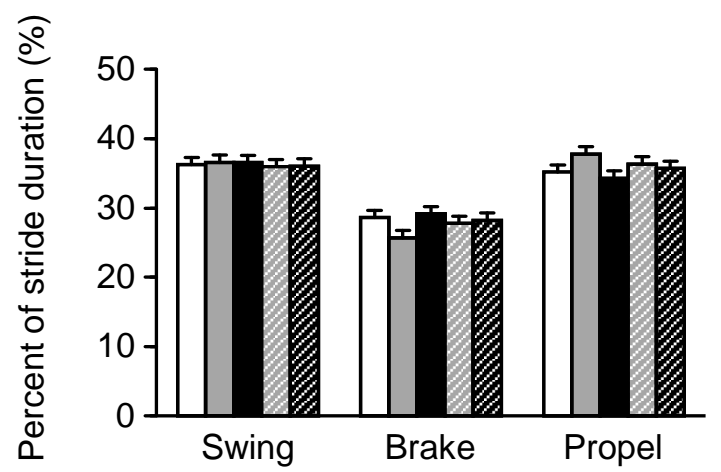

$\begin{aligned} & \square \text { Control } \\ & \square 0.1 \mathrm{mg} / \mathrm{kg} \\ & 0.5 \mathrm{mg} / \mathrm{kg}\end{aligned} \mid \mathrm{nAg} 10$
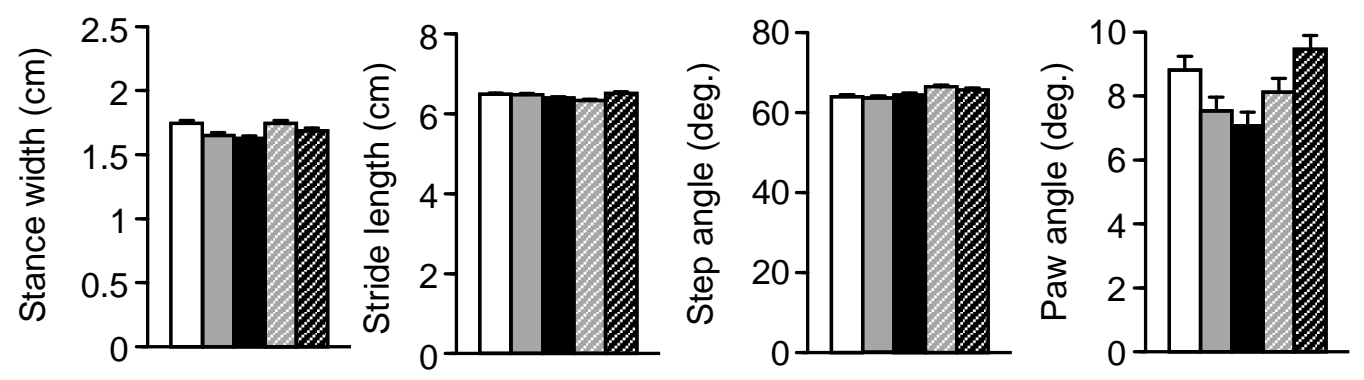

\section{Hind paw}
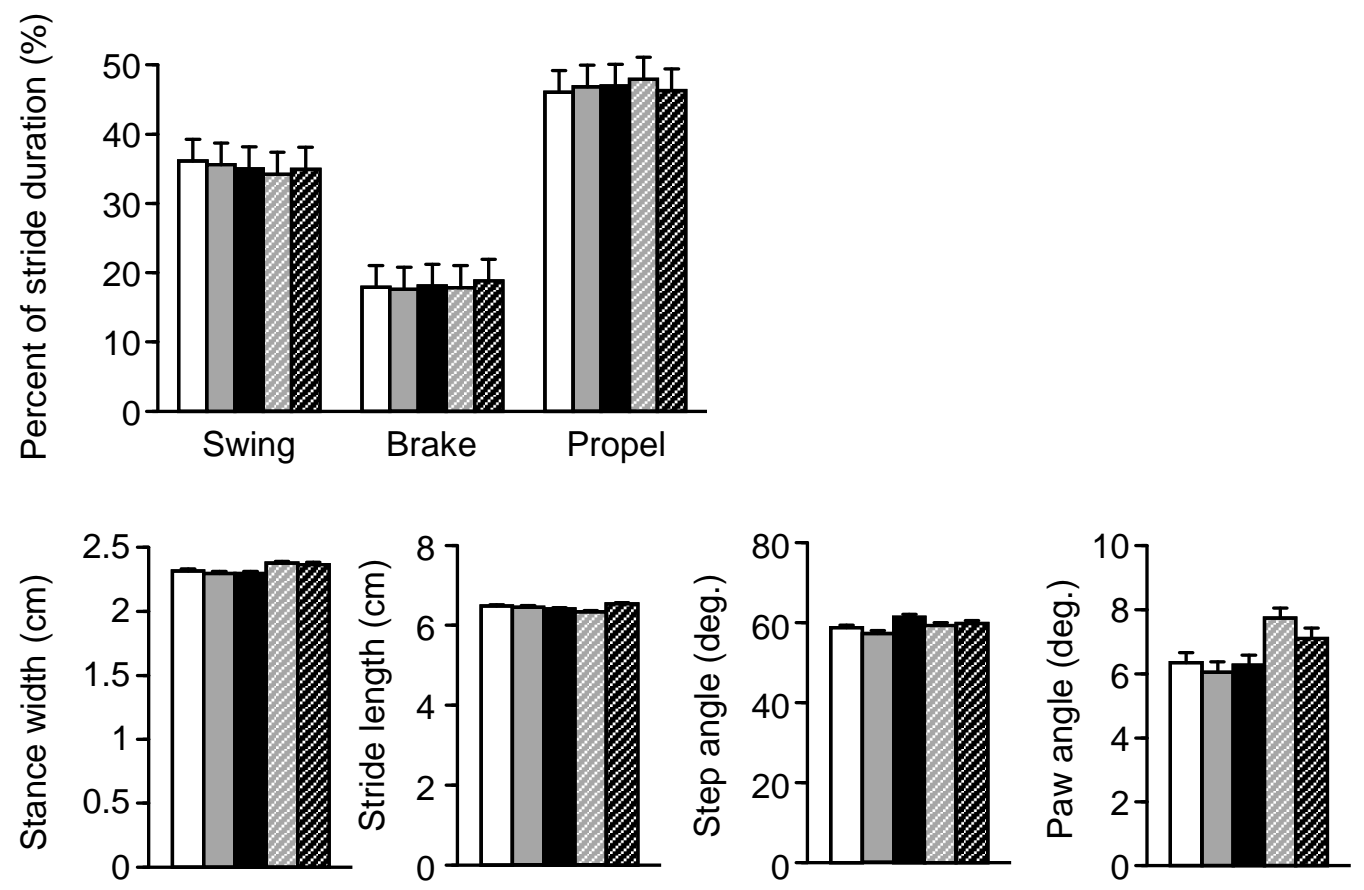

Supplementary Figure S36. Behavioral analyses of male offspring breast-fed by dams that received oral nAg10 or $\mathrm{Ag}^{+}$daily from PND 0 to 20, Part 5. Graphs of measured indices for gait analysis. Data are reported as means \pm SEMs $(n=16-20)$. 


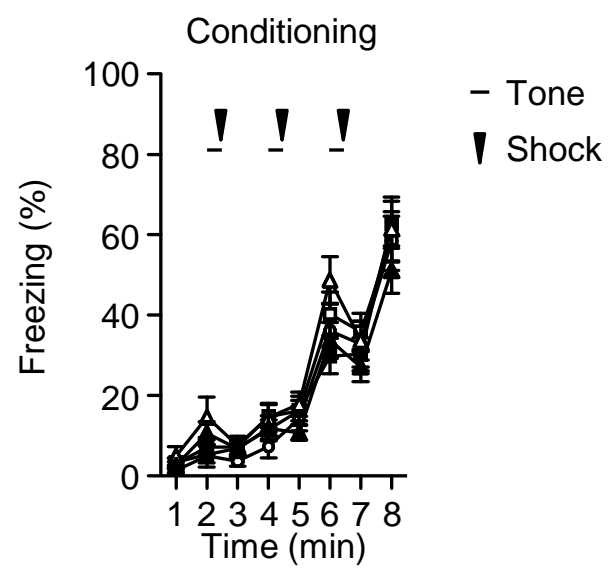

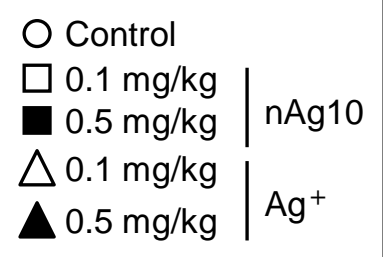

Day 2
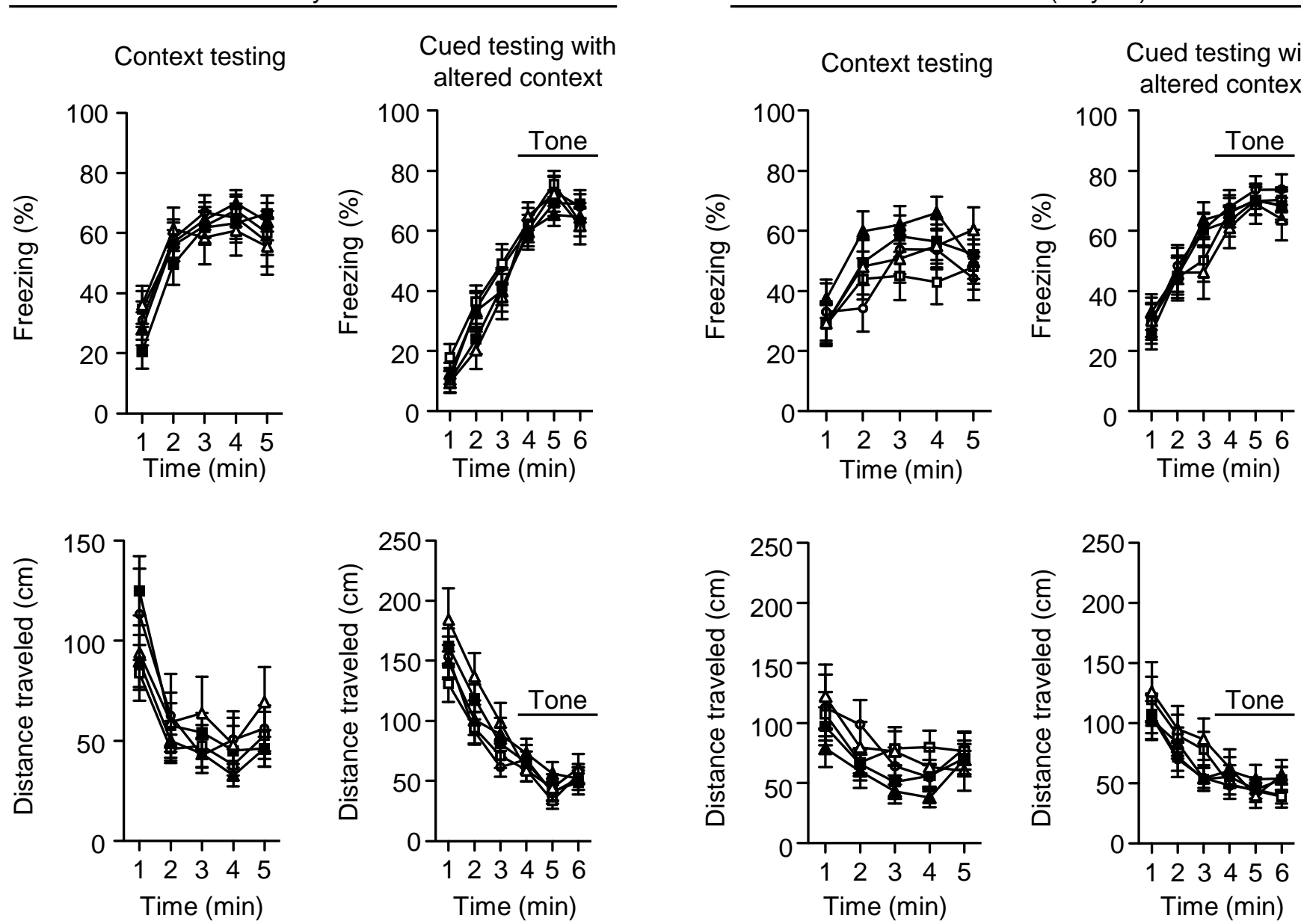

Supplementary Figure S37. Behavioral analyses of male offspring breast-fed by dams that received oral nAg10 or $\mathrm{Ag}^{+}$daily from PND 0 to 20, Part 6 . Graphs of measured indices for fear conditioning test. Data are reported as means \pm SEMs $(n=14-20)$. 